
July 1936

\title{
MEASUREMENTS OF FLAME VELOCITY BY A MODIFIED BURNER METHOD
}

\author{
By Francis A. Smith and S. F. Pickering
}

\section{ABSTRACT}

This paper describes a study of the application of the burner method to the determination of the velocity of propagation of flame relative to mixtures with air of various combustible gases. Observations have been made on the effect of varying the size of the burner port, of changing the velocity of flow of the mixture from the burner, of changing the composition of the mixture, and of different methods of measuring the flame and computing the result. All of these factors relate to problems of gas utilization.

The apparatus and procedure are described in detail. The relationships developed between the size and shape of the flame surface as related to the diameter of the burner port and the composition of the mixture lead to the following conclusions:

1. The most consistent results by the burner method, regardless of variations in the above conditions, are obtainable when the shape of the flame surface most nearly approximates a geometrical cone.

2 . Distortion at the tip and base of the flame may be minimized by using mixtures in nearly theoretical proportions.

3 . Measurements of the slope of the flame surface (at a point on the radius $0.7 r$ from the axis) involve a portion of the surface little or not at all affected by the distortion at the tip and base.

4. The adequate separation of the tip and base to leave a portion of the surface unaffected by distortion may be accomplished by the use of burners over $4 \mathrm{~mm}$ in diameter.

5. Measurements of the entire surface area may yield results considerably more in error on account of departures from the geometrical shape than those computed from measurements of the angle between the axis and the side of the flame surface at $0.7 r$ from the axis.

6 . The only points on the curves of two or more fuel gases which even approach suitability for a direct comparison between the different gases are the maxima.

An attempt has been made to derive the shape of the flame surface by the application consecutively of a series of facts and assumptions based on facts.

The flare at the base of the flame surface where it overhangs the burner port is explained in terms of the magnitude and direction of flow of the gas mixture rather than by a cooling effect of the port.

The gap between the flame and the metal port is considered to represent the distance required by the temperature gradient from the port to the flame front.

A gradient layer underlying the entire flame surface is postulated, with a thickness similar to that of the gap between the flame and the metal port.

The curvature of the upper part of the flame surface convex upward may be caused by a modification of the originally parabolic distribution of the velocity of flow of the combustible mixture, after leaving the burner tube, rather than by an increase in the flame speed caused by a higher initial temperature of the combustible mixture. The rounding off of the extreme tip, however, is doubtless caused by the overlapping of the thin gradient layers and may result in an actual increase in the flame speed to several times the speed in other parts of the flame surface. 
I. Introduction Page

II. Choice of method. 8

III. Description of the method... 10

IV. Apparatus and procedure..... 13

1. Manipulation of gases

2. Measurement of gases

3. Mixing of gases

4. By-pass cock

5. Flash-back trap

6. The burner

7. The camera

8. The goniometer

9. Treatment of the results

V. Dependence of numerical result upon experimental factors

1. Effect of mixture velocity

2. Effect of the size of the burner port and of the method of measurement of the photographs._. 22

3. Effect of the overhanging flame

4. A test of the applicability of the expression $\bar{D} \bar{V}=0.707 \bar{D}-30$

VI. The shape of the flame surface as a resultant of several variable components

VII. Summary and conclusions

VIII. References... 43

\section{INTRODUCTION}

The velocity with which flame is propagated in the combustible mixture issuing from the ports of a gas burner is one of the important factors which must be taken into account in any study of the performance and design of gas burners.

It was thought that a knowledge of the flame velocity in mixtures of the single combustible gases in varying proportions with air and with oxygen would be required if a means of calculating the flame velocity in complex mixtures of these constituents with air and oxygen was to be found. It was also desired to correlate the flame-velocity data with the conditions under which the flame flashes back through the ports of the burner, or blows off from them. Therefore, the measurement of the flame velocity in simple mixtures of a number of the constituents encountered in the various fuel gases was undertaken.

The fact that many workers using different methods obtain different results, which cannot be readily correlated or even compared on a common basis, makes the problem of determining flame velocities and applying the results a rather difficult one. There are several reasons for this. One source of confusion is that flame velocity, like "flame temperature", "ignition temperature", "explosive and inflammable limits", etc., has been too often considered to be a characteristic of a gas itself. Actually all of them are properties of the system as a whole, including usually the apparatus. Each of these socalled properties depends to so great an extent upon other factors that the identity of the combustible gas can be considered as only one of the several factors which, taken together, determine the numerical values in a given case. Such data must be used with the knowledge that the numerical values given may or may not be applicable to conditions which differ from those under which the measurements were made.

Furthermore, a direct comparison between two individual combustible gases with respect to flame velocity is not the simple matter it 
appears to be at first glance. For example, the data from the two gases may be obtained by the same method, with the same apparatus, and the comparison may be made (a) by substituting one combustible gas for the other in a gas-air mixture which is otherwise unchanged in composition and temperature. The two gases may be methane and propane, each constituting 7.5 percent of its mixture with air. An examination of the curves plotted in figure 5 shows that all that can be elicited from such a comparison is that the flame velocity in a very lean mixture containing 7.5 percent of methane is more than twice that in a very rich mixture containing 7.5 percent of propane. (b) The comparison may be made between mixtures, each of which contains the same percentage of the total air required for the complete combustion of the respective gases. The curves plotted in figure 4 show that such a comparison may be valid between methane and propane, but if either of these gases is compared with hydrogen in mixtures containing, for example, 80 percent of the air required for complete combustion, the same difficulties are encountered as before but not to such an extreme degree. Such comparisons are obviously invalid, and the alternative of choosing the maximum-speed mixtures as the only points on the curves which are much more than roughly comparable one with another must be accepted. Even with maximum-speed mixtures, the flame velocities obtained by different methods may be compared with validity only when each method yields the same result with a given mixture, the composition, temperature, and pressure being the same in each case.

In making use of data, care must be taken to select those which have been obtained by the method most nearly corresponding to the experimental or practical conditions with which the data are to be connected, until more is known than at present concerning the mechanism of each process. For example, if detonation is involved, data obtained with detonating mixtures should be used. If the interest is in the behavior of flames in closed vessels, use should be made of data so obtained. If the question concerns the velocity in space (relative to a stationary object) with which flame travels in tubes or tubular openings of various sizes in various materials, the results obtained by the use of corresponding (or similar) tubes may be applicable. If the velocity in space of flame in large tubes or in the open is in question, the data must come from work done in tubes of corresponding diameter.

\section{CHOICE OF METHOD}

A survey of the methods in use for determining flame velocities resulted in the selection of the bunsen-burner method for the present study, for a number of reasons.

The method of Bunsen [1], ${ }^{1}$ modified successively by Gouy [2], Michelson [3], Ubbelohde [4], and by Stevens [5], was found by Stevens and by the present authors to yield results which, in the case of $\mathrm{CO}-\mathrm{O}_{2}$ mixtures, were in surprisingly good agreement with results obtained by the "constant-pressure bomb" or "soap-bubble" method of Stevens [6]. Both methods permit the evaluation of the velocity of the combustible mixture in space, and the determination of the velocity of propagation of the flame relative to the combustible mixture.

1 The figures given in brackets here and throughout the text correspond to the numbered references at the end of this paper. 
The use of the burner appeared to involve fewer difficulties in the construction of the apparatus, was more readily adapted to use in the related problems of burner performance, and permitted the collection of flame-velocity data under conditions which approximate those to which they were to be applied.

It is recognized by the authors that the burner method in general may not be a particularly accurate one for the determination of absolute values for the rate of propagation of flame relative to the mixture in which the flame travels. However, the method herein described, as will be shown later, is suited to direct comparisons between the maximum flame velocities shown by various fuel gases under a given set of conditions with a precision of about 2 percent or better.

It was hoped that the apparatus and technique described in this paper would eliminate most of the objectionable features of the general burner method. It developed, however, that the numerical result obtained for the flame speed was not entirely independent of the diameter of the burner tube, a circumstance reported by Ubbelohde and Hofsäss [7] in 1913, but which has been neglected by many workers who have made use of various modifications of the burner method.

\section{DESCRIPTION OF THE METHOD}

The method in principle is the same as that employed by Bunsen [1], Gouy [2], Michelson [3], Ubbelohde [4], Mache [8], and Stevens [5], but was modified further in certain respects by the authors.

These modifications were, in large measure, refinements to determine or to control conditions with a view to eliminating variables, the effects of which might obscure those under investigation. The numerical result depends to so great an extent on the conditions of operation and the methods of measurement and computation, that careful control and careful specification of experimental conditions are essential. It seems desirable, therefore, to describe in some detail the apparatus and technique employed in the present work.

A brief review of the essential points of difference in the methods of some of the investigators named above may serve to clarify references to various modifications which have been made since Bunsen's original attempt to measure flame velocity by means of a burner.

Bunsen [1] assumed that the velocity of the flame front downward just exceeded the velocity of the gas mixture upward at the moment when the flame flashed back down the burner tube. Obviously this could be true only if the velocity of the stream of gas mixture was the same at the center of the burner tube as it was at the walls.

Gouy [2] probably sensed something wrong with Bunsen's assumption, for he at first considered the flame velocity to be equal to the product of the velocity of the gas mixture with the sine of the angle which the side of the flame cone made with its axis. Then finding that the surface formed by the flame front did not approximate sufficiently to a true cone, and that the result obtained depended upon what part of the flame front he used when he measured the angle, he eliminated the angle from consideration by setting the velocity of the flame equal to the volume rate of flow of the mixture divided by the area of the flame surface. This involves the concept of flame velocity as simply the rate of transformation of the mixture, without the necessity of considering the velocity of the gas mixture and its 
direction of flow. The two concepts would yield identical results if the flame surface were a geometrical cone with the burner port for a base.

Gouy determined the area of the flame surface from measurements of the image of the flame projected on a screen. Considering the figure as a surface of revolution, he obtained the area by integration.

Michelson [3] measured the volume rate of flow of the mixture and determined the actual area of the "cone" by treating measurements of enlarged photographs in the same way that Gouy had done.

Ubbelohde [4] concluded that the rounded tip and the curved base of the flame surface represented deviations from what he termed the "normal" flame velocity, so he measured the angle made by the "straight" portion of the flame surface with its axis, and computed the result as Gouy had done originally.

Stevens [5] was unable to obtain results with the burner which were in satisfactory agreement with the results he obtained with the "bubble" when he determined the area of a flame surface as Gouy and Michelson or Ubbelohde had done. He recognized, as did Ubbelohde, that the approximately conical flame surface was the resultant of several components, one of which was a mixture velocity which varied from practically zero at the walls of the burner tube to a maximum at the center. Stevens, therefore, decided to make use of only that part of the flame surface which resulted from gas mixture whose actual linear velocity was equal to the mean velocity over the cross section of the stream. He constructed on his photograph a triangle having as its base the cross section of the burner tip and sides parallel to the tangents to the flame surface at the part where the velocity of the mixture equalled the mean velocity. Considering this triangle as a section through the axis of a cone the area of the cone was easily calculated without integration from the measured altitude and base, and values obtained from it for the velocity of the flame front relative to $\mathrm{CO}-\mathrm{O}_{2}$ mixtures agreed with those obtained with the bubble so closely that the two methods, for many purposes, could be used interchangeably.

A number of other workers have adhered to Gouy's assumption, expressing flame velocity in terms of volume of combustible mixture per second divided by the area of the flame surface. Of these, some use the actual integrated area of the flame surface and others use the area of a geometrical cone having the burner port as a base. The area of this geometrical cone has been arrived at in various ways, among which are the following: $(a)$ by using the actual measured height of the flame cone; $(b)$ this cone height corrected by a factor designed to bring the numerical result into agreement with the results obtained by integrating the surface of revolution; $(c)$ by using the angle between the straight portion of the side of the flame and the axis. Since the area of the burner port divided by the lateral area of a geometrical cone of which the burner port forms the base is equal to $\sin \alpha$ (where $\alpha$ is the angle between the side and the axis of the cone), the cone may also be defined by the burner port and the angle $\alpha$. All of these expressions would lead to the same numerical result were the flame surface a geometrical cone.

Instead of measuring and computing the area of the cone as Stevens had done, the present authors have chosen to measure directly the angle $\alpha$ between the tangents and the axis, which, together with the burner port, is sufficient to define the cone. Instead of dividing 
the volume rate of flow of the combustible mixture by the area of the cone to obtain the flame velocity, it has been divided by the area of the burner port, thus obtaining the average linear velocity of flow of the mixture. The angle is measured at that part of the flame surface where the local velocity of flow of the mixture is equal to the average velocity. The sine of the angle $\alpha$, multiplied by the average velocity of the mixture, then gives the same numerical value for the flame velocity as does the other method. This is essentially a com-

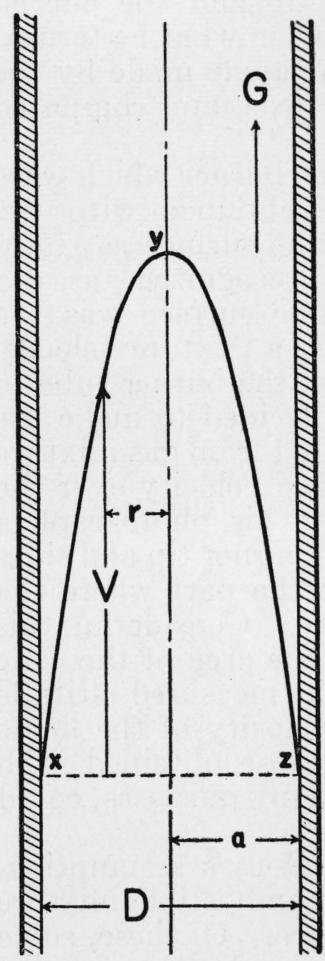

Figure 1.-Velocity diagram of fluid in laminar flow through a tube. bination of the original method of Gouy [2] with those of Michelson [3], Ubbelohde [4], and Stevens [5].

The distance, from the center of a tube, at which the velocity is the mean for the tube as a whole, is, theoretically, equal to 0.707 times the radius of the tube. Twice this distance will be called the "mean velocity diameter" and will be designated $D_{\bar{v}}$. This factor is constant for tubes of all sizes and for all fluids, as will be evident from the following relationship, which is familiar in hydraulics. ${ }^{2}$ In a tube of radius $a$ (fig. 1) the curve $\mathrm{x}, \mathrm{y}, \mathrm{z}$ represents the velocity $V$ at a distance $r$ from the axis of the stream of fluid of viscosity $\mu$ moving under a pressure gradient $G$. Then the velocity $V$ of an annular ring of fluid of any radius $r$ will be $V_{r}=$ $\frac{G}{4 \mu}\left(a^{2}-r^{2}\right)$; and the mean velocity $\bar{V}$ will be $\bar{V}=$
$\frac{G a^{2}}{8 \mu}$. Placing $V_{r}=\bar{V}$ and solving for $r ; \frac{G}{4 \mu}$ $\left(a^{2}-r^{2}\right)=\frac{G a^{2}}{8 \mu} ; a^{2}-r^{2}=\frac{a^{2}}{2} ; r^{2}=\frac{a^{2}}{2} ; r=\underset{\sqrt{2}}{a}=\frac{a}{1.414}=$

\section{$0.707 a$. Therefore, $D_{\bar{\nabla}}=0.707 \mathrm{D.}^{3}$}

When measuring the photograph, $D_{\bar{v}}$ must be multiplied by a magnification factor. $D$ is determined by measuring the diameter of the burner port with a micrometer, and the magnification factor is obtained from the photograph of a scale substituted in the place of the flame in the axis of the burner tube. A pair of dividers is adjusted to the computed $D_{\bar{t}}$ distance, and moved upon the negative image of the flame front on the photographic plate until an outside diameter equal to this distance has been located, when marks are made on the image by pressing the points of the dividers into the emulsion.

The marked plate is then mounted in a goniometer, illuminated from behind with a diffuse light, the intensity of which can be varied to give the best visibility of the image, and rotated until the cross hair of a reading telescope is judged to be tangent to the image of the flame surface at the mark, on first one side of the flame and then on the other. The angle through which the plate was rotated between settings is read on a vernier scale, and is equal to $2 \alpha$.

\footnotetext{
2 Derivation supplied by E. Buckingham, National Bureau of Standards.

3 The validity of the application of the factor 0.707 to the measurement of the photographs of flames is treated in the section on the effects of experimental factors, page 30 .
} 
Angle measurements were made by two observers, one making settings and the other reading and recording the angles. After two settings on each side of the flame, the observers changed places and the observations were repeated, giving four values of $2 \alpha$. The average of these observations was used in calculating the flame velocity, or rate of transformation of the mixture, which has been designated $S_{\mathrm{T}}$.

The volume rate of the gas mixture was divided by the area of the burner port computed from $D$, giving the mean linear velocity of the gas mixture. This has been designated $S_{\mathrm{M}}$. The velocity of propagation of the flame front, in a direction normal to its surface and relative to the combustible mixture in which it moves, is then given by the equation $S_{\mathrm{T}}=S_{\mathrm{M}} \sin \alpha{ }^{4}$

\section{APPARATUS AND PROCEDURE}

\section{MANIPULATION OF GASES}

A diagram of the apparatus used for obtaining photographs of the flames is shown in figure 2. Those combustible gases which could not be utilized directly from cylinders, such as manufactured gas, and acetylene, were stored in two water-sealed gas holders, $\mathrm{H}$, having a combined capacity of about 70 cubic feet. The holders were equipped with piping which permitted mixing the gas in the holders by means of a small rotary compressor. The gas from the holders was delivered, saturated with water, to the measuring apparatus at a pressure of 5 to 6 inches of water above the barometric pressure. "Bottled gases" and others which could be obtained in and utilized directly from cylinders under pressure were delivered directly from the cylinder. The flow was in all cases accurately controlled by a good needle valve, $V_{1}$, placed far enough ahead of the capillary flowmeter, $\mathrm{M}_{1}$, to avoid disturbing the flow through the capillary.

The air used was taken from the low-pressure laboratory supply, passed through a saturator $\mathrm{S}$, the temperature of which was measured in order that the proportion of water in the air might be known, and, thence, through a diaphragm pressure-reducing valve, $\mathrm{D}$, past a tee to which was attached a 12 -inch rubber pilot-balloon bag, $\mathrm{P}$, to equalize pressure fluctuations, past a similar tee to which was attached a bleeder valve, $V_{2}$, for the same purpose, and then through the needle valve, $V_{3}$, used to control the flow through a capillary flowmeter, $\mathrm{M}_{2}$, similar to that used to measure the gas.

These precautions proved insufficient to eliminate all fluctuations in the rate of flow of the gas mixture through the burner port, the tip of the cone showing rapid and irregular pulsations which made a sharply defined photographic image impossible. Some of these pulsations were definitely traced to pressure fluctuations in the atmosphere of the room, caused by the ventilating fans. Others, which persisted with the fans shut down and the windows open, were imposed by the movements of the air outside the building.

A tile wall was built across one side of the laboratory, inclosing a space of about 700 cubic feet, which contained all the apparatus except the saturator and gas holders. The wall was plastered on both sides and all joints were sealed with bituminous cement. Openings in the wall connecting with the fume exhaust were covered with doors made tight with a seal of rubber tubing, as was the main door-

1 The apparent assumptions that flame travel is in a direction normal to its surface, and that the velocity of travel is proportional to $\sin \alpha$, are justified by an application of Huyghens' principle to the geometrical derivation of the flame surface, which is treated later on p. 36. 


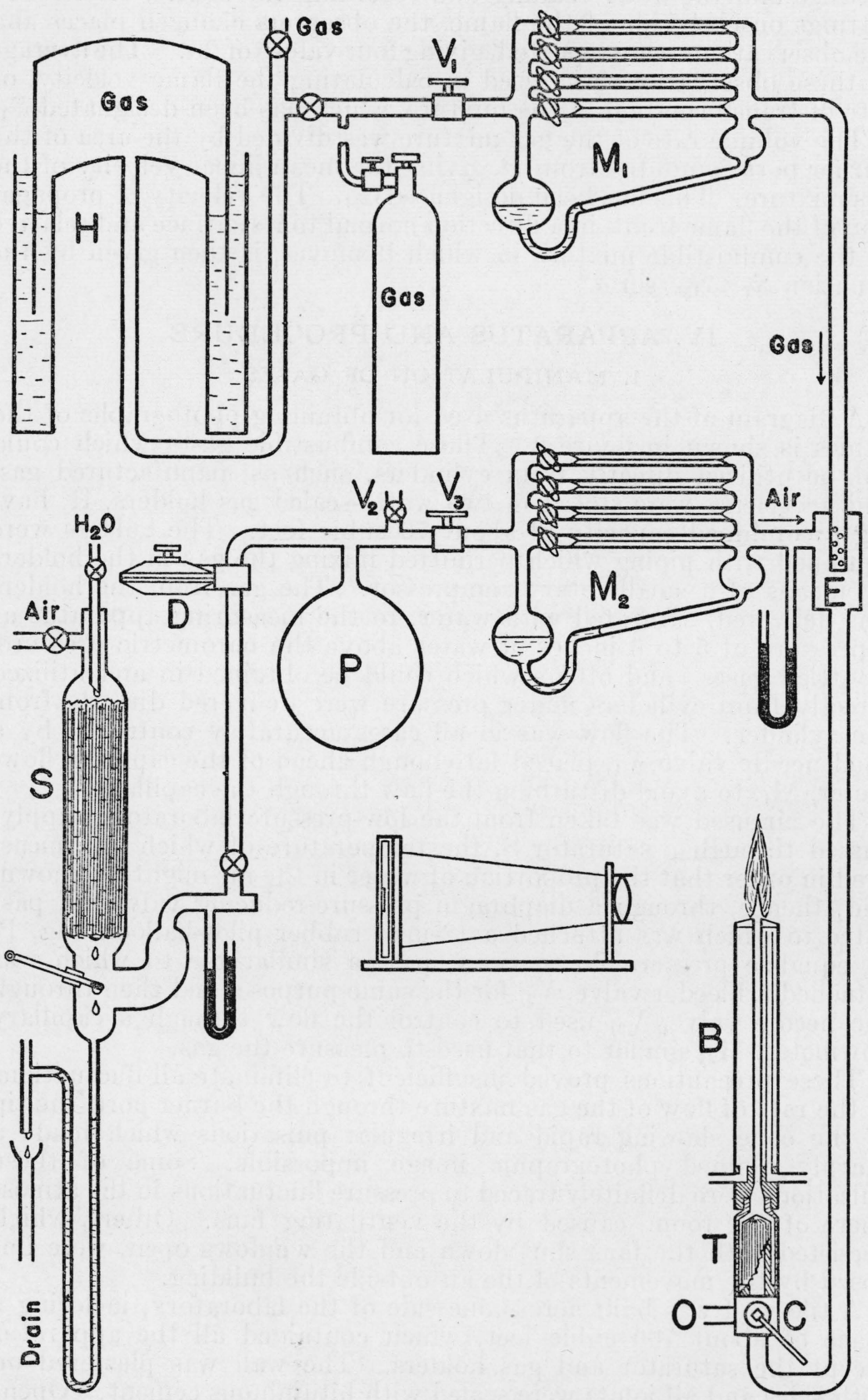

Figure 2.-Diagram of the apparatus used to control and photograph flames. 
way. The entire inner surface of the room was given two coats of bituminous paint to seal the plaster and provide a black interior to minimize reflections. This treatment eliminated the pulsations of the flame to such an extent that perfectly sharp images resulted from exposures as long as 10 minutes.

The effectiveness of the air saturator, S, was checked by weighing the water absorbed by magnesium perchlorate trihydrate from a measured volume of air. The amount of water found in the air from the saturator agreed with the percentage calculated within 0.1 percent, assuming saturation at the observed temperature and pressure of the saturator.

\section{MEASUREMENT OF GASES}

The gases were measured by passage through glass capillary flowmeters, $M_{1}$ and $M_{2}$, equipped with slope gages. Each flowmeter consisted of a unit made up of four capillary tubes, $20 \mathrm{~cm}$ long and having different diameters, sealed together in parallel. Each capillary was preceded by a stopcock so that by a suitable selection of capillaries any desired rate of flow up to $205 \mathrm{ml}$ per second could be obtained at a differential pressure within the range of the manometer.

The manometers were tubes about $4 \mathrm{~mm}$ in diameter and $1 \mathrm{~m}$ long. A meter stick firmly fixed to the tube served as a scale. The tubes were inclined with the upper end $10 \mathrm{~cm}$ higher than the lower end, to which was attached the reservoir for the manometer liquid.

A light liquid petrolatum was used because its low vapor pressure reduced to a minimum contamination of the gases measured, and because it was free from meniscus troubles. It was dyed red to facilitate reading the position of the meniscus.

Both flowmeters were calibrated with air against a 0.1-cubic-foot wet displacement meter, which in turn had been calibrated against a standard 0.1-cubic-foot bottle. During the calibration of the flowmeters the temperature of the room was maintained at $30 \pm 0.2^{\circ} \mathrm{C}$, and all work was done with the room at $30 \pm 1^{\circ} \mathrm{C}$, in order to avoid the introduction of a temperature-correction factor in the use of the calibration.

The resistance to the flow of the mixture from the outlet of the flowmeters to the tip of the burner was kept at a minimum, and this, with the low differential pressure across the capillaries, kept the average pressure of the gas in the capillary from exceeding atmospheric pressure by more than 1 percent at the maximum rate of flow and with the smallest burner. This made a pressure correction for the flowmeter calibration unnecessary. The differences in the temperature and pressure at which the air was saturated in the wet meter and the temperature and pressure at which it was saturated in the previously described air saturator were taken into account in computing the volume passed by the meter. In all cases, except those involving very low rates of flow, the meter was timed for an integral number of complete revolutions in order to avoid errors arising from variations in the volumes of the four compartments of the meter drum. The time was measured with a stop watch which had been checked against the standard second signal and found accurate to 1 part in 600 . 
The capillary tubes were calibrated individually and with all connected in parallel. Smooth curves were drawn through the points, and the maximum deviation of the points from the curve on all curves but one for the individual tubes was 1 part in 460 . The maximum deviation from the curves for the combined tubes was 1 part in 300 . The smallest capillary of the group required an excessively long time to complete one revolution of the meter, so parts of a revolution were used, and only three points were obtained, which showed a maximum deviation of 1 part in 125 .

By operating the air flowmeter and gas flowmeter simultaneously, with the wet meter connected at the common outlet, it was then determined that the rate of flow indicated by the air flowmeter, plus the rate indicated by the gas flowmeter, was equal to the total rate of flow as indicated by the wet meter. This relationship made possible the computation of the composition of the mixtures supplied to the burner from the flowmeter readings and a knowledge of the composition of the constituents. Mixtures prepared in this manner were analyzed chemically, and the computed composition agreed with that determined by the analysis. The average percentage deviation of the points from the calibration curves justifies the assumption that the composition of mixtures may be computed in this way with a precision of about \pm 0.1 percent.

At the outset the authors desired to avoid the necessity of making a complete calibration of the flowmeter for each gas to be measured. Accordingly, it was decided to make use of a viscometer to obtain the ratio of the time required for the effiux of any gas to the time required for the efflux of the same volume of air under the same head and at the same temperature, $30^{\circ} \mathrm{C}$. This time ratio for each gas was used as a correction factor applied to the air calibration.

Unfortunately, the composition of a mixture computed in this way differed by 3 or 4 percent from the results of the analysis. This led to the discovery that the correction factor was different for different tubes and varied with the rate of flow. It was necessary, therefore, to use some of each fuel gas to calibrate as many of the tubes as were required directly against the wet meter. This was done at a sufficient number of points to establish a curve for each tube showing the variation of the correction factor with the rate of flow.

With some gases the factor was small, differed but little with different tubes, and was practically constant at all rates of flow. With other gases the reverse was true.

\section{MIXING THE GASES}

The combustible gas leaving the gas flowmeter passed through a metal tube which extended downward into a metal box only slightly larger than the tube. The gas flowed from the tube through a number of holes in the sides. The air entered the box from the air flowmeter and flowed downward past the holes from which gas was issuing and thence out through a metal pipe which led to the burner. The front of the box was closed by a window of thin cellophane. The device, shown at $E$ in figure 2, thus served the dual purpose of mixer and explosion head, protecting the flowmeters from the effects of explosions, which sometimes passed the flash-back trap.

The mixing of the gases was completed during the subsequent passage through 2 feet of iron pipe, two ells, a by-pass cock, C, and a 
flash-back trap, T, on the outlet of which was screwed the burner, B. The volume of the fittings intervening between flowmeters and burner was kept small in order that when the composition of the mixture at the outlet of the flowmeters was changed by adjusting the needle valves, the new mixture would replace the old within a few seconds, even at a low rate of flow. At the same time the volume of the fittings was large enough and the flow sufficiently disturbed to insure a perfectly homogeneous mixture at the base of the burner.

\section{BY-PASS COCK}

A large-bore cock of the plug type, $\mathrm{C}$ in figure 2, was placed immediately below the flash-back trap, T. It was fitted up as a tee-cock so that a $90^{\circ}$ turn of the plug would cut off the flow of mixture from the flash-back trap and burner, and permit unrestricted flow out of the side opening, $\mathrm{O}$, through a tube to a ventilator flue. This made it possible to extinguish flames which had flashed down the burner tube, $\mathrm{B}$, and were burning in the flash-back trap, without cutting off the supply of gas or air, and without disturbing the flowmeter readings.

\section{FLASH-BACK TRAP}

A flash-back trap, shown at T, consisted of a cylindrical cast-iron dome with walls about $5 \mathrm{~mm}$ thick. Slots about 0.3 to $0.4 \mathrm{~mm}$ wide were sawed through the sides of this dome lengthwise. A sufficient number of slots provided a combined area of opening as large as the cross section of the pipe, so that no significant impediment to the flow resulted. The dome was screwed to the outlet of the by-pass cock, and, in turn, was surrounded by a brass cylinder, slightly larger, which screwed on at the base of the slotted dome. This brass cylinder terminated at the top in a screw fitting to which various burners could be attached as desired.

The purpose of the trap was to prevent flames which flashed down the burner tube from traveling back to the flowmeters. Should this occur the supply of gas would have to be cut off until the flame was extinguished, which would necessitate readjusting the flow to the desired rate. The flames being unable to pass through the narrow slots against the high velocity, burned on the outside of the dome which, having thick walls, readily dissipated the heat evolved for a short time. The flame was then easily extinguished when the stream of mixture was diverted by means of the by-pass cock. The slotted dome was a part of a burner designed by the National Lighting Co., for use with acetylene.

\section{THE BURNER}

Several burners of different diameters were used, the construction of which is indicated at B. All were made of seamless brass tubing, the inside surface of which was cylindrical and polished smooth. The burner tubes were mounted on duplicate bases, so that they might be readily interchanged. They were inclosed in water jackets to prevent preheating the gas mixture to an unknown and variable temperature. Any uncertainty in the temperature of the mixture would cause a corresponding uncertainty in its volume rate and consequently in the velocity with which it issued from the burner tip. 
The temperature of the mixture was maintained at $50^{\circ} \mathrm{C}$ during the studies on all except the first three gases. This was done to prevent the condensation of moisture from the flame around the rim of the port. In the case of the first three, hydrogen, carbon monoxide, and acetylene, the temperature was approximately $30^{\circ} \mathrm{C}$. Subsequent investigation, to be reported in another paper, showed that the effect of changing the temperature by $20^{\circ} \mathrm{C}$ in this temperature range was not sufficient to justify repeating the work on these three gases.

The gas mixture was preheated on its way to the burner by a nichrome coil heated electrically and placed directly in the gas stream. Water at $50^{\circ} \mathrm{C}$ was circulated through the burner jacket, and the temperature of the unlighted mixture was measured at frequent intervals by means of a thermocouple swung into position just above the burner port. A detailed description of this equipment will constitute a part of the subsequent paper mentioned above.

The lengths of the burner tubes were, in all cases, more than 40 times their diameters. This was ample to permit eddies and turbulence introduced by the flow through the various fittings to die out and insure laminar or streamline flow of the mixture before it reached the tip of the burner. A permanent condition of turbulent flow would result only in case the value of the Reynolds number $R$ is allowed to exceed $2,300 .^{5}$ The range of operation was kept below this limit.

\section{THE CAMERA}

The camera used to photograph flames for measurement in the determination of flame velocity was made in the woodworking shop of this Bureau from a sketch supplied by the authors. A few parts, bellows, plateholders, and lens with its mechanism, came from other sources. The lens was a U.S.4 rapid rectilinear of the Bausch and Lomb Optical Co. The bellows could be extended to 20 inches, which permitted focusing at short object distances, as well as magnification in the case of small flames. Ordinarily the magnification factor was kept at about 2 .

Six pictures were made on each 5 - by 7 -inch plate by shifting the plateholder past a vertical 1-inch focal plane stop placed in the center of the field. The exposure time varied according to the intensity and actinic quality of the light from the various flames. Times as long as 4 minutes were required in the case of the hydrogen flame. In most cases the time was about 1 second.

The brightly illuminated scale used to determine the magnification factor was used as the object upon which to focus the camera, the image being formed on a fine-ground glass plate substituted for the plateholder.

\section{THE GONIOMETER}

The instrument with which the angle $\alpha$ was determined was designed to permit rapid measurement, with a minimum of fatigue to the eyes and nerves of the observers, maximum freedom from personal errors, and the highest practicable precision. The instrument shown in figure 3 was found to be very much better, in all respects, than any

$R=\frac{D \times V \times d}{\mu}$, and

$D=$ diameter of burner tube, expressed in centimeters.

$V=$ velocity of fluid, in centimeters per second.

$d=$ density of fluid, in grams per cubic centimeter.

$\mu=$ viscosity of fluid, in $\mathrm{cgs}$ units. 


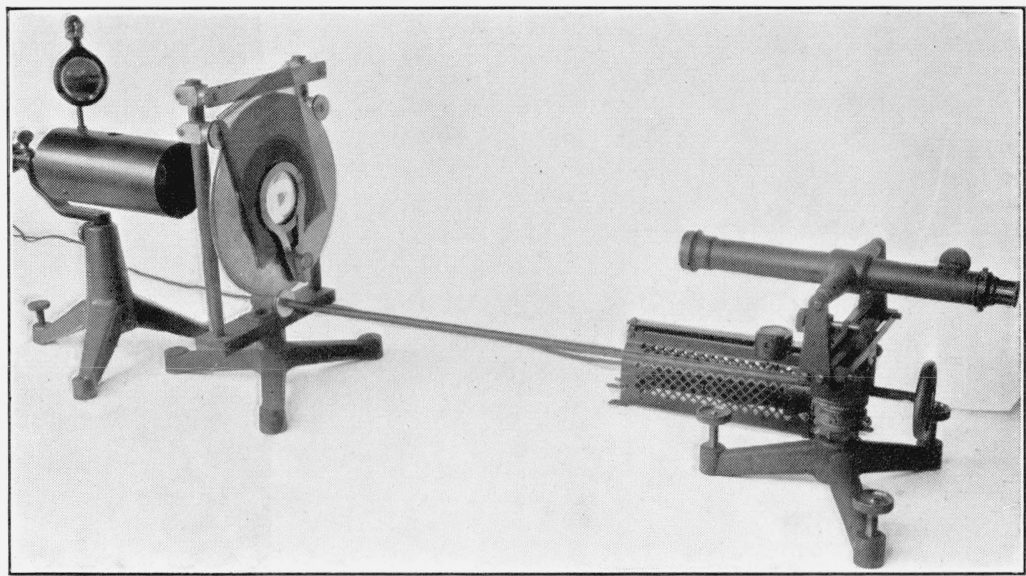

FIGURE 3.-Goniometer and reading telescope for measuring the angle between the two sides of the flame surface.

In making the photograph, a mirror was mounted over the illuminator in the hope of showing vernier and scale on the back of the goniometer. 
of the four or five devices which had previously been used, improved upon, and discarded. The time required and the resulting fatigue were greatly reduced and the precision was improved by decreasing the number of operations and by simplifying those which remained. The personal element was eliminated from all of the operations except that in which the observer was required to set the cross hair of the reading telescope tangent to the curved flame surface at a marked point. The radius of curvature of the flame surface was not constant, the curve resembling a parabola, so the operation involved personal judgment trained by a study of the geometry of the figures, and some practice, before settings could be reproduced with desirable precision. In order to reduce the effect of this personal factor, two observers made settings alternately and their results were averaged. The precision attainable was a function of the character of the flame, the character of the negative, and of the curvature of the flame surface. The average deviation of all the angles measured from the means of their groups was 2.3 percent.

\section{TREATMENT OF THE RESULTS}

The numerical results obtained in this investigation add little to the mass of data already on record, and are presented here primarily to serve as a basis for the investigation and discussion of the effects upon them of changing several experimental variables.

The data are in approximate agreement with those of other workers with the burner method and, in the case of $\mathrm{CO}-\mathrm{O}_{2}$ mixtures, with the bubble method of Stevens. Flame speeds derived from measurements in 1-inch horizontal glass tubes are, however, very nearly twice those obtained with similar mixtures by the former two methods, probably because the combustible mixture in which the flame traveled was itself moving along the tube. Chapman and Wheeler [9] show that this occurs in the case of tubes open at both ends.

All the data have been plotted as shown in figure 4. Smooth curves have been drawn through the points so that the sum of the positive and negative deviations of the points from their curve is very small.

The composition of the mixtures has been expressed in terms of the air in the mixture, as compared to the total amount required for the complete combustion of the gas. The abscissas, therefore, represent primary air, expressed as percentages, of the total air required. (Primary air is that which is mixed with the gas before combustion. The remainder of the air required for complete combustion must come from the atmosphere surrounding the flame, and is called secondary air.)

This means of expressing the composition places all the gases as nearly as is possible upon the same basis, not only on the score of the air required for complete combustion, but on that of heat of combustion as well, for the heat evolved is at least roughly proportional to the oxygen consumed.

The data have also been plotted in figure 5 , in which the composition is expressed in terms of the percentage of combustible gas in the mixture. This has been done only to facilitate comparison with the data of other investigators and to illustrate certain points under discussion. 


\section{DEPENDENCE OF NUMERICAL RESULT UPON EXPERIMENTAL FACTORS}

In order to provide a basis for the investigation of the effects of changing experimental factors on the numerical result obtained, the following assumption has been made.

In any combustible mixture of gases, of given composition, temperature, and pressure, there is a definite fixed value for the velocity of propagation of flame relative to the gas mixture. Consequently, if different values are obtained by different means, it must be concluded either that one of the supposedly fixed experimental conditions was

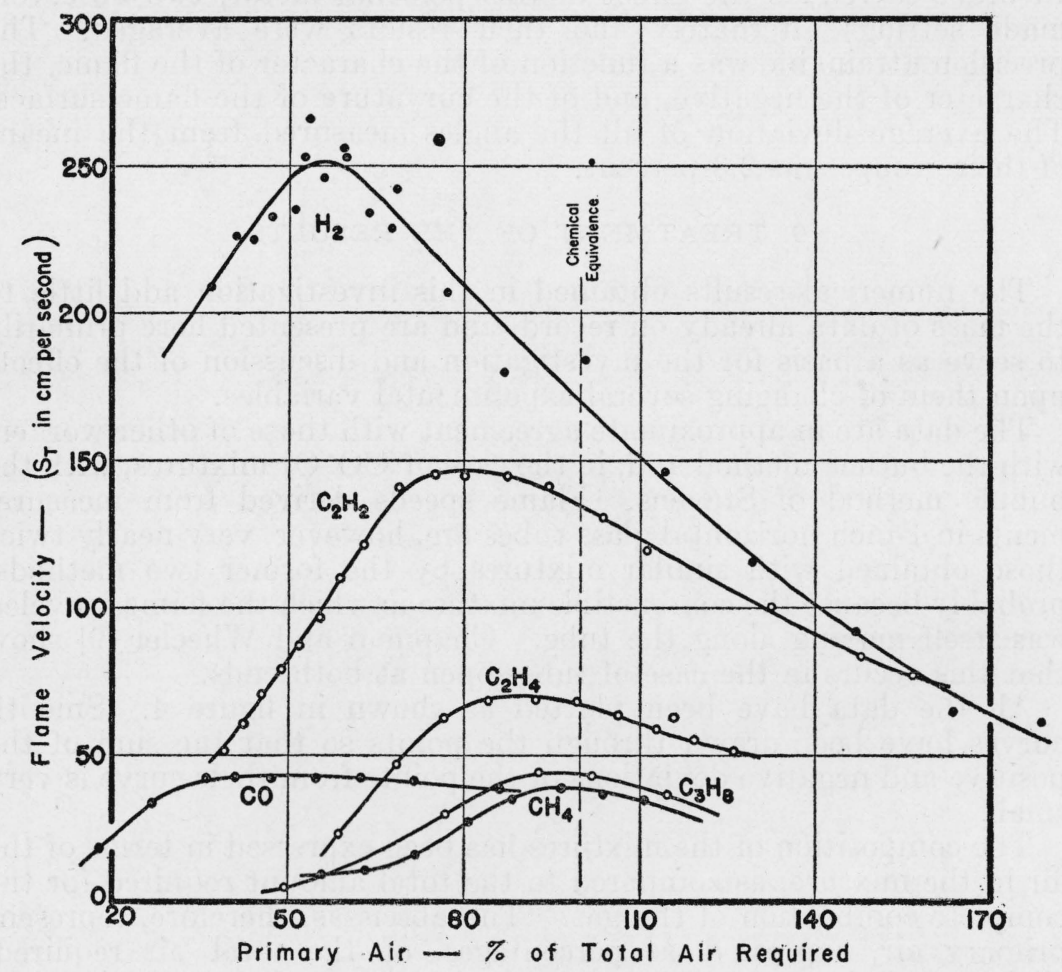

Figure 4.-Flame-velocity curves for six fuel gases.

The curves are plotted to place these gases on a common basis with respect to the air required for combustion, and nearly so with respect to heating value.

not what it was supposed to be, or that the differences in the numerical result have been imposed by differences in the methods of measurement and computation, or by the apparatus.

On this basis, the degree to which the numerical result is found to be independent of the method or apparatus used to obtain it may be used as a criterion of the extent to which that result approaches the supposedly correct definite fixed value assumed above to exist.

An attempt has been made to discover the cause of differences in the numerical result obtained when the flame velocity relative to comparable gas mixtures has been computed under varying conditions. 
The variables were average velocity of mixture, composition, size of port, the angle $\alpha$, and the method of measurement and computation. Insofar as it was practicable they were varied one at a time.

\section{EFFECT OF MIXTURE VELOCITY}

With a gas mixture of given flame velocity, the magnitude of the angle $\alpha$ depends upon the velocity with which the mixture flows from the burner port. Increasing $S_{\mathrm{M}}$ decreases $\alpha$, and vice versa. It was desired to know whether the product $S_{\mathrm{M}} \sin \alpha$, which is the flame velocity $S_{\mathrm{T}}$, was dependent upon the magnitude of $S_{\mathrm{M}}$.

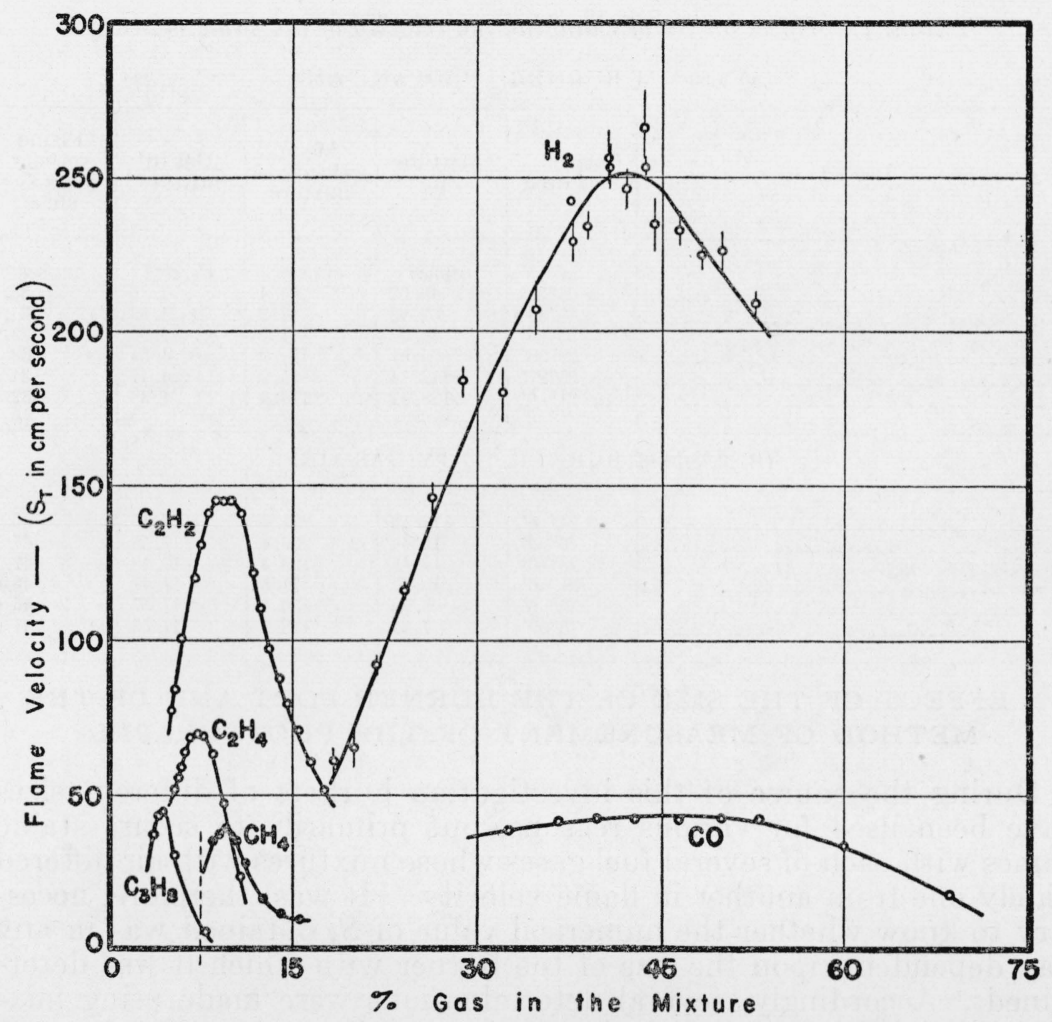

Figure 5.-The flame-velocity curves of figure 4 plotted in the usual manner, with "percentage of gas in the mixture" as abscissa.

Accordingly, the following test was applied to the largest and to the smallest of the burners used in this study, which were $9.60 \mathrm{~mm}$ and $2.75 \mathrm{~mm}$ in diameter, respectively. A gas was selected for each which would accommodate a large change in $S_{\mathrm{M}}$ between the limits at which the flame flashed back or lifted off when burning the mixture in which $S_{\mathbf{T}}$ was a maximum. The mixture of maximum $S_{\mathrm{T}}$ was chosen, because at or near the maximum small changes in composition have least effect upon $S_{\mathrm{T}}$. The flowmeters were adjusted to give mixtures of very nearly the same composition at several different rates of flow, the highest rate being nearly three times the lowest 
rate in the case of the large burner, and nearly twice the lowest rate in the case of the small burner. $S_{\mathbf{T}}$ was computed for each rate.

The results are shown in table 1. Regardless of allowable variations in $S_{\mathrm{T}}$, because of variations in composition from the maximum-speed mixture, the average deviation from the mean value of $S_{\mathrm{T}}$ was 0.67 cm per second, or 2.0 percent, in the case of the large burner, and $0.70 \mathrm{~cm}$ per second, or 1.5 percent, in the case of the small burner. This variation corresponds approximately to the precision of the measurements. The conclusion is that the numerical result obtained is independent of the velocity of flow of the gas mixture within these limits. $^{6}$

TABLE 1.-Effect on $S_{\mathbf{T}}$ of changing the velocity of the same mixture

(A) 9.60-MM BURNER. PROPANE-AIR.

\begin{tabular}{|c|c|c|c|c|c|}
\hline Record & $\begin{array}{c}\text { Angle } \\
\text { measured }\end{array}$ & $\begin{array}{c}\text { Mixture } \\
\text { rate }\end{array}$ & $\begin{array}{c}\text { Mean } \\
\text { velocity of } \\
\text { mixture }\end{array}$ & $\begin{array}{c}\text { Gas in } \\
\text { mixture }\end{array}$ & $\begin{array}{c}\text { Flame } \\
\text { velocity } \\
S_{T}=S_{M} \\
\sin \alpha\end{array}$ \\
\hline 1 & $\begin{array}{l}2 \alpha \\
63^{\circ} 38^{\prime} \\
46^{\circ} 33^{\prime} \\
35^{\circ} 23^{\prime} \\
29^{\circ} 36^{\prime} \\
25^{\circ} 27^{\prime} \\
21^{\circ} 6^{\prime}\end{array}$ & $\begin{aligned} \mathrm{m} 1 / \mathrm{sec} \\
46.62 \\
62.43 \\
80.02 \\
94.51 \\
112.14 \\
128.42\end{aligned}$ & $\begin{aligned} \mathrm{cm} / \mathrm{sec} \\
64.4 \\
87.2 \\
111.7 \\
131.2 \\
155.9 \\
178.4\end{aligned}$ & $\begin{aligned} \text { Percent } \\
4.76 \\
4.69 \\
4.59 \\
4.54 \\
4.41 \\
4.38\end{aligned}$ & $\begin{array}{r}\mathrm{cm} / \mathrm{sec} \\
33.9 \\
34.5 \\
33.9 \\
33.5 \\
34.3 \\
32.7\end{array}$ \\
\hline
\end{tabular}

(B) 2.75-MM BURNER. CITY GAS-AIR.

\begin{tabular}{|c|c|c|c|c|c|}
\hline 1 & $\begin{array}{l}24^{\circ} 6^{\prime} \\
26^{\circ} 2^{\prime} \\
28^{\circ} 16^{\prime} \\
31^{\circ} 6^{\prime} \\
36^{\circ} 6^{\prime} \\
43^{\circ} 39^{\prime}\end{array}$ & $\begin{array}{r}13.16 \\
12.44 \\
11.48 \\
10.17 \\
8.93 \\
7.65\end{array}$ & $\begin{array}{l}221.7 \\
209.4 \\
193.3 \\
171.3 \\
150.4 \\
128.8\end{array}$ & $\begin{array}{l}17.55 \\
17.56 \\
17.48 \\
17.47 \\
17.57 \\
17.53\end{array}$ & $\begin{array}{l}46.3 \\
47.2 \\
47.2 \\
46.0 \\
46.6 \\
47.9\end{array}$ \\
\hline
\end{tabular}

\section{EFFECT OF THE SIZE OF THE BURNER PORT AND OF THE METHOD OF MEASUREMENT OF THE PHOTOGRAPHS}

During the course of this investigation burners of different sizes have been used for various reasons, but primarily to secure stable flames with each of several fuel gases whose mixtures with air differed widely one from another in flame velocity. It was, therefore, necessary to know whether the numerical value of $S_{\mathrm{r}}$ obtained was in any way dependent upon the size of the burner with which it was determined. Accordingly, several determinations were made using mixtures of air with the same fuel gas (city gas) on each of four burners having diameters of $9.60,6.50,4.45$, and $2.75 \mathrm{~mm}$, respectively, maintained at $50^{\circ} \mathrm{C}$. The resulting curves are shown in figure 6 .

In the course of a description of a method and apparatus which incorporates many of the features of the apparatus described in this paper, Corsiglia [10] states that direct comparisons between burners of different sizes showed them to be in agreement within the limits of experimental error. The method of meas urement and computation by which the flame-velocity data were derived by him from the photographic negatives was essentially a combination of those of

- Ubbelohde and Koeliiker [4] have determined the maximum flame velocities in $\mathrm{H}_{2}$-air mixtures for different mixture velocities. The maxima were constant for the two points in which the flow in the burner tube remained laminar, $R<2,300$, but the velocity of the mixture measured next was $1,300 \mathrm{~cm}$ per second giving $R=>2,400$, and showing an increase in the value of the maximum flame velocity. 
Michelson [3] and Gouy [2]. The enlarged image of the original negative projected upon a ground-glass surface was traced, and the necessary measurements were made from the tracing. The area of the surface of revolution was computed in a manner which probably differed somewhat from that of Gouy and Michelson, no integration being required except that performed by a planimeter in determining the area of the axial section delineated by the photograph.

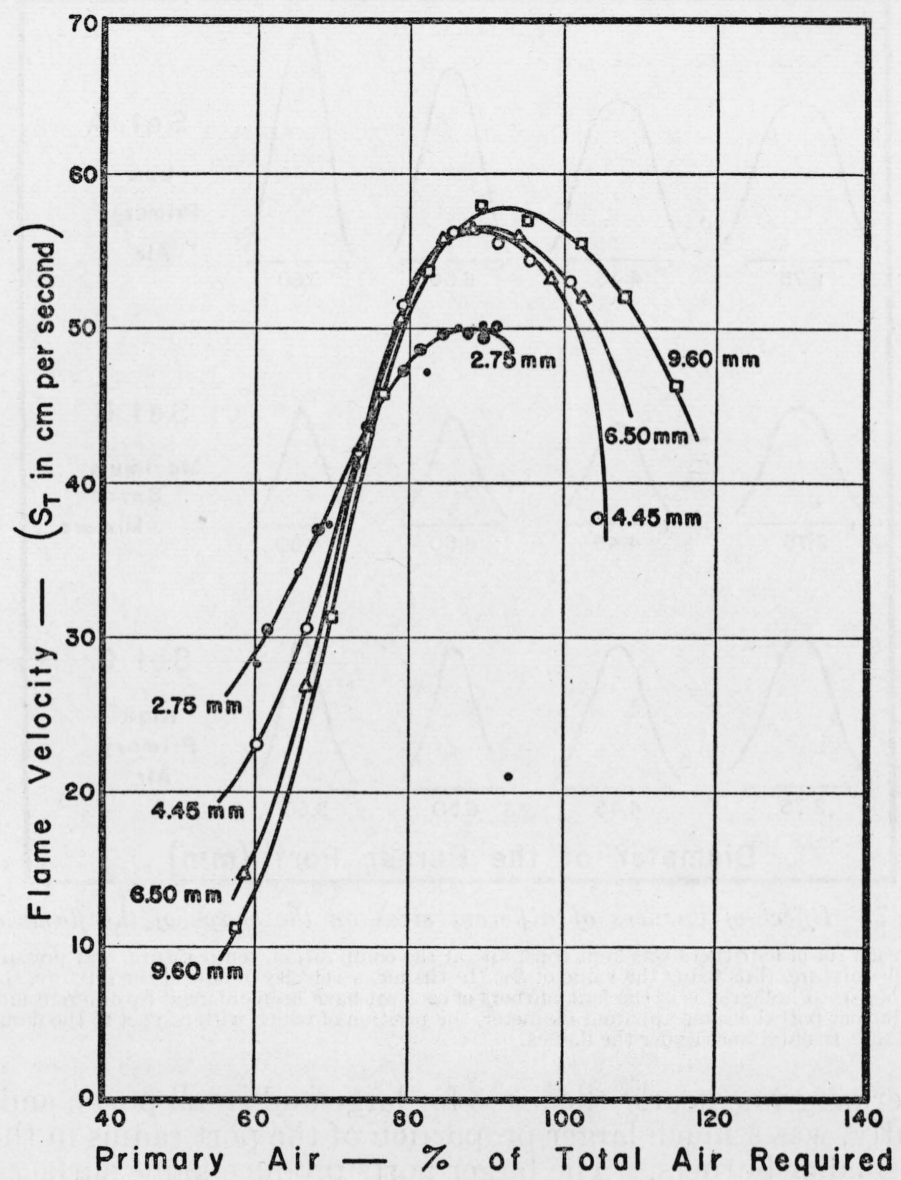

Figure 6.-Flame-velocity curves abtained with burners of different sizes burning mixtures of the same gas with air.

In view of the discrepancies which appear in figure 6 between the curves obtained with the four burners by the method in which the angle $\alpha$ is used as the basis of computation, it was considered desirable to make some comparative measurements to see whether the agreement between results from the different burners was improved by the use of the area of the flame surface in computing the flame 
velocity. ${ }^{7}$ Differences in the shape of the flame surface when the same mixture is burned on burners of different sizes immediately suggested themselves as a possible cause of such discrepancies. Such differences in shape have long been noted. ${ }^{8}$

For example, the base of the flame surface is somewhat larger in diameter than the port, and this "overhang" appeared to be greater with small ports. A few preliminary measurements indicated that

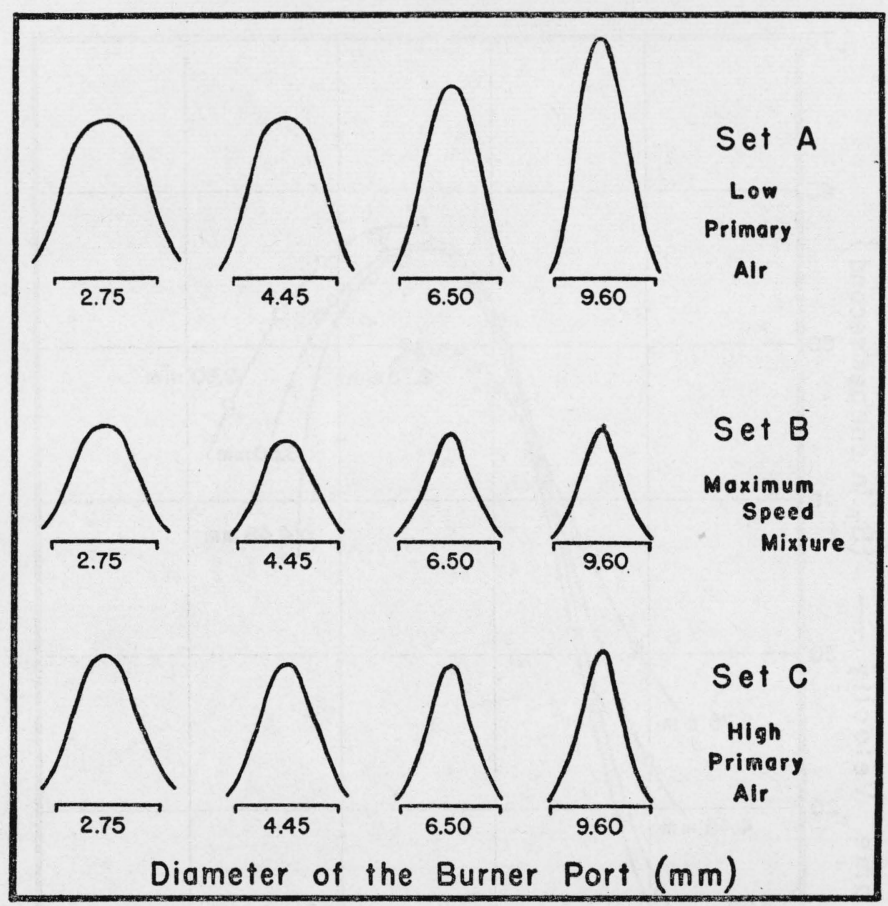

FiguRE 7.-Effect of burners of different sizes on the shape of the flame surface

Within each set of four there was kept constant (a) the composition, temperature, and pressure of the combustible mixture, thus fixing the value of $S_{\mathrm{T}}$; (b) the mean velocity of flow of the mixture, thus fixing the value of $S_{\mathrm{M}}$. Photographs of the four burners of each set have been enlarged by different amounts to give each burner port the same apparent diameter, the position of which with respect to the flame is indicated by the horizontal lines under the flames.

the overhang was nearly the same for large and small ports, and, consequently, was a much larger proportion of the port radius in the case of the smaller burners. The larger ports produce flame surfaces with relatively sharp tips and sides which are concave near the base.

7 Computations based on measurements of the "cone height" involve, for the most part, determinations of the area of the flame surface made from time to time and the use of a correction factor which, with the cone height, will give this area. Such a procedure is, therefore, roughly equivalent to that of Corsiglia, provided such correction factors have been determined over a sufficient range of flame shapes to determine the variation of the factor with the shape of the flame.

8 Ubbelohde and Koelliker [4] describe a method by which the form of the inner cone may be derived from the parabolic distribution of the mixture velocity across the diameter of the port. They conclude that burners of different sizes will yield different results, but that the differences become negligible with large burners and with mixtures of nearly theoretical proportions. 
With the smaller ports the flame surface tends to become thimble shaped, the tip becoming broadened into a dome. Similar changes in the shape of the flame surface occur with the same port as the proportion of air in the mixture is reduced.

In order to facilitate direct comparison of the flame surfaces resulting from the use of ports of different sizes, and to compare the results obtained by the two methods of measurement and computation, a set of photographs were made under the following conditions. The composition of the mixture and its temperature were kept constant, thus fixing the actual flame velocity and, consequently, the product $S_{M} \sin \alpha$. The rate of flow was adjusted for each burner so that the mixture flowed from each port with the same average velocity, $S_{\mathrm{M}}$. Any differences in the product $S_{\mathrm{M}} \sin \alpha$ would then be concentrated in the angle $\alpha$. The detection of differences in shape between flame surfaces of different size was simplified by enlarging the negatives by appropriate factors, which gave all the ports the same apparent diameter. If changing the diameter of the port by substituting burners of different size had no effect, all the negatives should, under these conditions, have the same angle $\alpha$, the same area of flame surface, and the same shape.

A set of negatives was made in this way for each of three mixtures which contained the following proportions of the total air required for complete combustion: 103 percent (high primary air), 90 percent (maximum $S_{\mathbf{T}}$ ), and 62 percent (low primary air). Figure 7 shows

TABLE 2.-Effect of changes of port diameter upon the area of the flame surface and upon the angle $\alpha$; and the consequent effect on the numerical value of flame velocity calculated from the angle as compared with that calculated from the area

SET A. LOW PRIMARY AIR

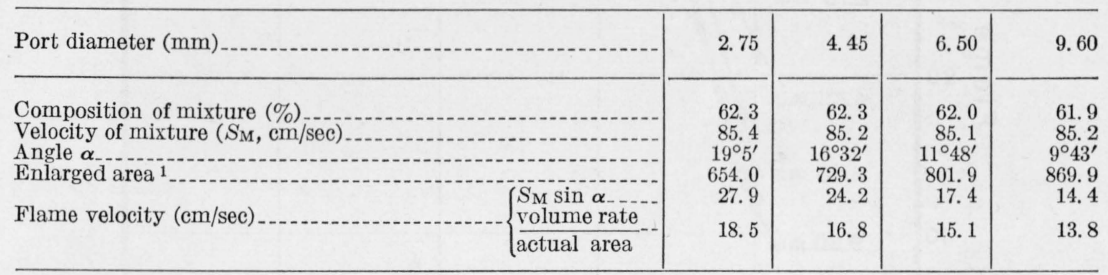

SET B. MAXIMUM-SPEED MIXTURE

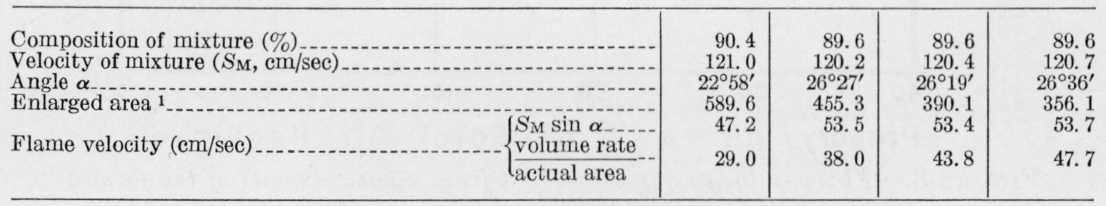

SET C. HIGH PRIMARY AIR

\begin{tabular}{|c|c|c|c|}
\hline Composition of mixture $(\%)$ & 103. 2 & 103.5 & 100. 7 \\
\hline Velocity of mixture $\left(S_{M}, \mathrm{~cm} / \mathrm{sec}\right)$ & 140. 2 & 140.0 & 140.8 \\
\hline Angle $\alpha$ & $19^{\circ} 4^{\prime}$ & $20^{\circ} 8^{\prime}$ & $20^{\circ} 13^{\prime}$ \\
\hline Enlarged area 1 & 644.4 & 560.9 & 483. 7 \\
\hline$\left\{\begin{array}{l}\mathrm{S}_{\mathrm{M}} \sin \alpha \\
\frac{\text { volume rate }}{\text { actual area }}\end{array}\right.$ & $\begin{array}{l}45.8 \\
30.7\end{array}$ & $\begin{array}{l}48.2 \\
35.9\end{array}$ & $\begin{array}{l}48.7 \\
41.3\end{array}$ \\
\hline
\end{tabular}

1 The enlarged area is the area of the flame surface, in arbitary units, measured after the flames have been brought to a common basis for comparison, by enlargement of all ports to the same apparent diameter. If changing the size of the port had no effect upon the shape of the flame, and if the flame base was congruent with the port, all four areas within a given set would be equal, as well as the angles. 
the outlines of the resulting flame surfaces. A line drawn beneath each flame represents the approximate position and apparent diameier of the port, and shows qualitatively the extent to which the base of the flame differs in radius and in elevation from the port on which it was formed. Table 2 shows the diameters of the ports, the composition and velocity of the mixture, the angle $\alpha$, the area of the enlarged surface, ${ }^{9}$ and the flame velocity as derived from the angle and also from the actual area of the flame surface in each case.

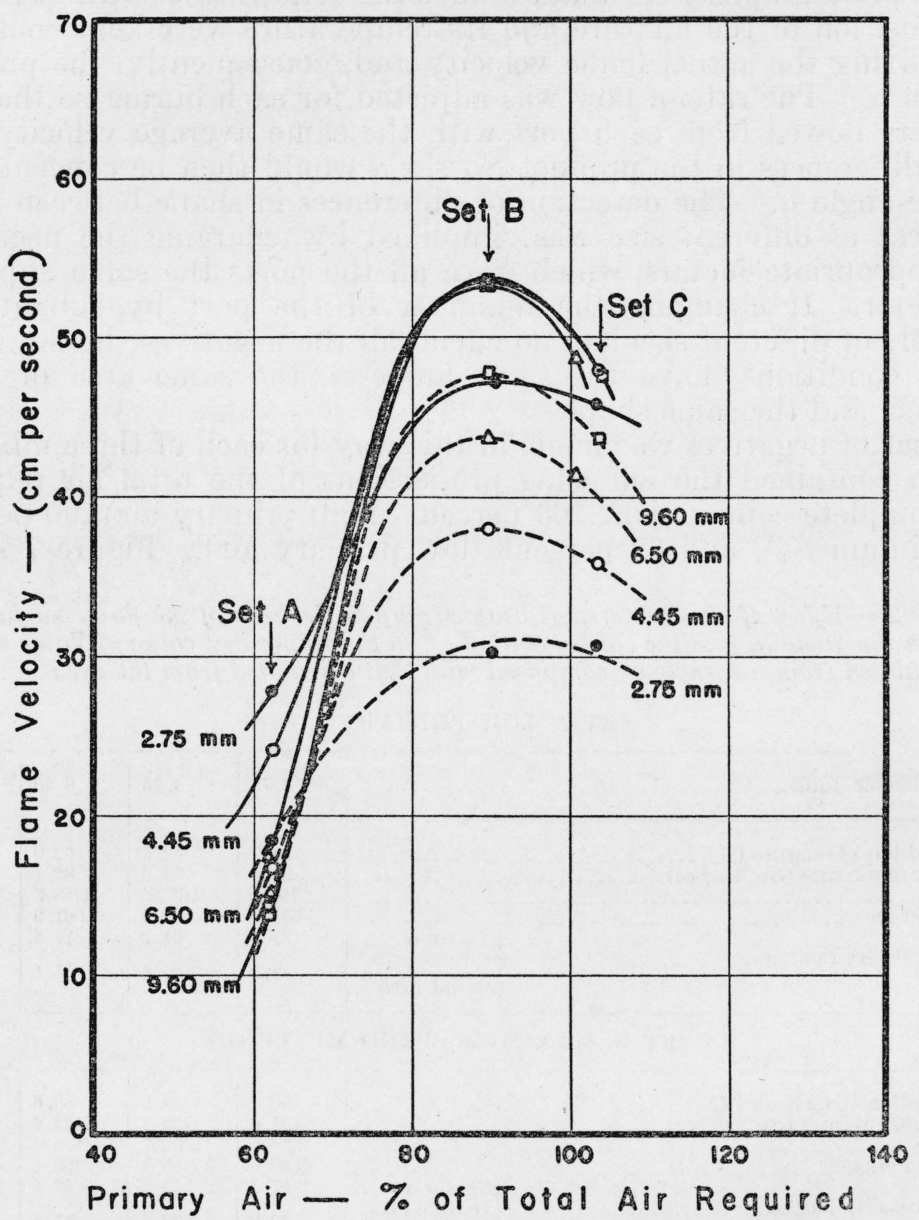

Figure 8.-Flame-velocity curves derived from measurements of the flames of figure 7.

The solid curves result from measurements of the angle. The dotted curves result from measurements of the area of the flame surface by the method of Corsiglia.

Figure 8 shows the flame-velocity curves resulting from the two methods of measurement and computation. The solid curves are the result of measurements of the angles, and the broken curves result from measurements of the surface area. By reference to table 2 it may be seen that within each set the composition of the mixture and its average velocity were kept substantially the same with each of the four burners. In sets B and C, the angle $\alpha$ is surprisingly constant

- See footnote to table 2, page 25. 
for the three larger burners, but is somewhat smaller with the $2.75-\mathrm{mm}$ burner in each case. In consequence, the flame velocity, as computed from the angle, also is nearly the same for each of the three larger burners in sets B and C, and with the smallest burner it is somewhat lower: Set A (low primary air) differs markedly from the other two sets in several respects. Not only is the angle not constant, but the smallest burner shows the largest instead of the smallest angle. The angle decreases progressively as the size of the burner is increased, and the numerical value for the flame velocity varies accordingly. This is illustrated graphically in figure 8 by the divergence of the solid curves below 75 percent of the total air required.

In none of the sets is the area of the surface the same for the various burners, but the area decreases progressively in sets B and C, and it causes a corresponding increase in the numerical value for flame velocity computed from the area, as the size of the burner is increased. This is illustrated in figure 8 by the divergence of the broken curves above 67 percent of the total air required. Set A, again, differs from the other two, showing a progressive increase in area and a corresponding decrease in the computed flame velocity as the size of the burner is increased.

Both methods of computation result in numerical values for the flame velocity which vary with the size of the burner port. In rich mixtures, the smaller the burner the higher is the apparent flame velocity. ${ }^{10}$ In lean mixtures, the smaller the burner the lower is the apparent flame velocity.

When computed from angle measurements the numerical values for flame velocity were substantially the same in the vicinity of the maximum with burner ports from $9.60 \mathrm{~mm}$ down to $4.45 \mathrm{~mm}$ in diameter. The $2.75-\mathrm{mm}$ burner showed a result about 11 percent lower at the maximum. In the rich mixtures the agreement was very poor, the $2.75-\mathrm{mm}$ burner showing a numerical result twice that shown by the $9.60-\mathrm{mm}$ burner.

When computed from area measurements, the numerical values for flame velocity are substantially the same for all the burners at about 67 percent of the total air required and diverge markedly in both directions. The $2.75-\mathrm{mm}$ burner shows a result over 30 percent less than that shown by the $9.60-\mathrm{mm}$ burner at the maximum. In the rich mixtures the spread of the results from all the burners is only about one-third as great as the spread shown when the results are computed from angle measurements. The curves for the $9.60-\mathrm{mm}$ burner computed by both methods are in good agreement from about 60 to 75 percent of the total air required.

As has been stated previously in this paper, excellent agreement was found between the maxima of the flame-velocity curves for $\mathrm{CO}-\mathrm{O}_{2}$ mixtures (containing the same amount of water vapor in both cases), one curve being obtained from computations based on the angle of the flame surface on a $3.85-\mathrm{mm}$ burner, and the other curve from results obtained by Stevens using the bubble method. In view of the above, and of the findings of Ubbelohde and Koelliker [4] and Ubbelohde and Hofsäss [11], it is concluded that when the burner method is used, computations on the basis of the angle of the flame

\footnotetext{
10 Ubbelohde and Hofsäss [11] discuss some of the sources of error inherent in several of the methods of measuring the cone and computing the flame velocity. They mention that the result obtained depends upon the secondary combustion and is too high. This error disappears as the composition of the mixture approaches the theoretical, and it is larger with smaller burners.
} 
surface at the mean velocity diameter yield results which are substantially correct for mixtures in which the flow is laminar, in which the flame velocity is near its maximum, and for burners not much smaller than $4 \mathrm{~mm}$ in diameter.

It is also concluded that only if the shape of the flame surface did not depart markedly from that of a geometrical cone could computations based on the actual area of the flame surface be expected to yield substantially the same results as those based on the angle, and only then could either be considered to be approximately correct. This requires that the tip of the flame surface have a reasonably sharp point, and that the area of its base exceed the area of the burner port by only a negligible amount. These conditions exist only in the vicinity of the maximum flame velocity and on relatively large ports. Few of the flames from which figure 8 is derived sufficiently approximate this condition.

That the same numerical result was obtained for the maximum flame velocity on all but the smallest of the four burners when the computation was made on the basis of the angle, shows that the angle is affected much less than the area by changes of burner size.

\section{EFFECT OF THE OVERHANGING FLAME}

It has been mentioned that if the base of the flame had the same diameter as the burner port, and if changing the size of the port had no effect upon the shape of the flame surface, the areas of the surfaces of two or more flames, when treated as shown in figure 7 , should be equal. Reference to figure 7 makes it apparent that the flame base is larger than the port. This is true not only in mixtures low in primary air, as mentioned by Corsiglia, and in which it is very pronounced, but all of the negatives made during this study show that overhang always occurs to some extent. ${ }^{11}$ In many cases the radius of the flame base was over 30 percent larger than the radius of the port.

There is no question that such differences must exert considerable influence upon the results obtained when the flame velocity is computed by different methods, such as those discussed above, but it is improbable that the effects upon the flame velocity set forth in table 2 can be accounted for wholly on this basis. In order to determine the magnitude of the overhang, measurements were made on the negatives used in the determination of flame velocity. These measurements embrace seven gases, mixtures ranging from low to high primary air, the same gas mixture on ports of different size, and the same mixture on the same port at different mixture velocities. The relation of overhang to the composition of the mixture, to the size of the port, and to the mixture velocity may be brought out most simply by a study of the measurements of the flames shown in figure 7, and of those from which the curves of figure 6 and the data of table 1 (B) are derived. Table 3 presents the data from the sources just mentioned. The averages of overhang measurements for each port and each mixture are shown in table 4.

${ }_{11}$ Ubbelohde and Koelliker [4] mention that the bases of most inner cones project laterally out over the burner wall and are suspended an appreciable distance above it. The explanation given does not seem entirely satisfactory, and this question will be discussed in another part of this paper. 
TABLE 3.-Overhang as related to composition, port size, and mixture velocity

\begin{tabular}{|c|c|c|c|c|c|c|}
\hline \multirow{3}{*}{ Port diameter } & \multicolumn{6}{|c|}{ Composition of mixture $-\%$ of the total air required } \\
\hline & \multicolumn{2}{|c|}{$62.5 \%$} & \multicolumn{2}{|c|}{$89.5 \%$} & \multicolumn{2}{|c|}{$103.5 \%$} \\
\hline & Overhang & $S_{M}$ & Overhang & $S_{M}$ & Overhang & $S_{M}$ \\
\hline $\mathrm{mm}$ & $\mathrm{mm}$ & $\mathrm{cm} / \mathrm{sec}$ & $\mathrm{mm}$ & $\mathrm{cm} / \mathrm{sec}$ & $\mathrm{mm}$ & $\mathrm{cm} / \mathrm{sec}$ \\
\hline $2.75 \ldots$ & $\left\{\begin{array}{r}0.4 \\
.5 \\
.5\end{array}\right.$ & $\begin{array}{r}143 \\
85 \\
144\end{array}$ & $\begin{array}{r}(a) .4 \\
.5 \\
.5 \\
.4\end{array}$ & $\begin{array}{r}129-222 \\
121 \\
193\end{array}$ & 0.5 & 140 \\
\hline $4.45 \ldots$ & $\begin{array}{r}1.0 \\
.9\end{array}$ & $\begin{array}{l}85 \\
95\end{array}$ & .6 & $\begin{array}{l}129 \\
120\end{array}$ & $\begin{array}{l}.5 \\
.6\end{array}$ & $\begin{array}{l}145 \\
140\end{array}$ \\
\hline $6.50_{-}$ & .8 & 85 & .5 & 106 & .5 & 120 \\
\hline 0.00 & .8 & 81 & .6 & 120 & .6 & 141 \\
\hline 9.60 & $\begin{array}{l}.7 \\
.6\end{array}$ & $\begin{array}{l}85 \\
89\end{array}$ & .5 & $\begin{array}{l}121 \\
118\end{array}$ & $\begin{array}{l}.5 \\
.3\end{array}$ & $\begin{array}{l}140 \\
133\end{array}$ \\
\hline
\end{tabular}

a Six flames of table 1(B) all had overhangs of $0.5 \mathrm{~mm}$, but $S_{\mathrm{M}}$ varied from 129 to $222 \mathrm{~cm} / \mathrm{sec}$.

TABLE 4.-Averages of the data of table 3

\begin{tabular}{|c|c|c|c|c|c|}
\hline \multirow[b]{2}{*}{ Port diameter } & \multicolumn{3}{|c|}{$\begin{array}{c}\text { Composition of the mixture- } \% \text { of total } \\
\text { air required }\end{array}$} & \multicolumn{2}{|c|}{$\begin{array}{l}\text { Average overhang for } \\
\text { the port }\end{array}$} \\
\hline & $\begin{array}{c}62.5 \% \\
\text { Avg } \\
\text { overhang }\end{array}$ & $\begin{array}{c}89.5 \% \\
\text { Avg } \\
\text { overhang }\end{array}$ & $\begin{array}{c}103.5 \% \\
\text { Avg } \\
\text { overhang }\end{array}$ & Distance & $\begin{array}{l}\text { Percentage } \\
\text { of port } \\
\text { radius }\end{array}$ \\
\hline $\begin{array}{l}\quad \mathrm{mm} \\
4.45 \\
6.50 \\
9.60\end{array}$ & $\begin{array}{r}\mathrm{mm} \\
0.5 \\
.9 \\
.8 \\
.6\end{array}$ & $\begin{array}{r}\mathrm{mm} \\
0.5 \\
.6 \\
.6 \\
.4\end{array}$ & $\begin{array}{r}\mathrm{mm} \\
0.5 \\
.6 \\
.6 \\
.4\end{array}$ & $\begin{array}{r}\mathrm{mm} \\
0.5 \\
.7 \\
.6 \\
.5\end{array}$ & $\begin{array}{r}\text { percent } \\
36 \\
31 \\
\mathbf{1 8} \\
\mathbf{1 0}\end{array}$ \\
\hline Avg. overhang for the mixture........ & .7 & .5 & .5 & & - \\
\hline
\end{tabular}

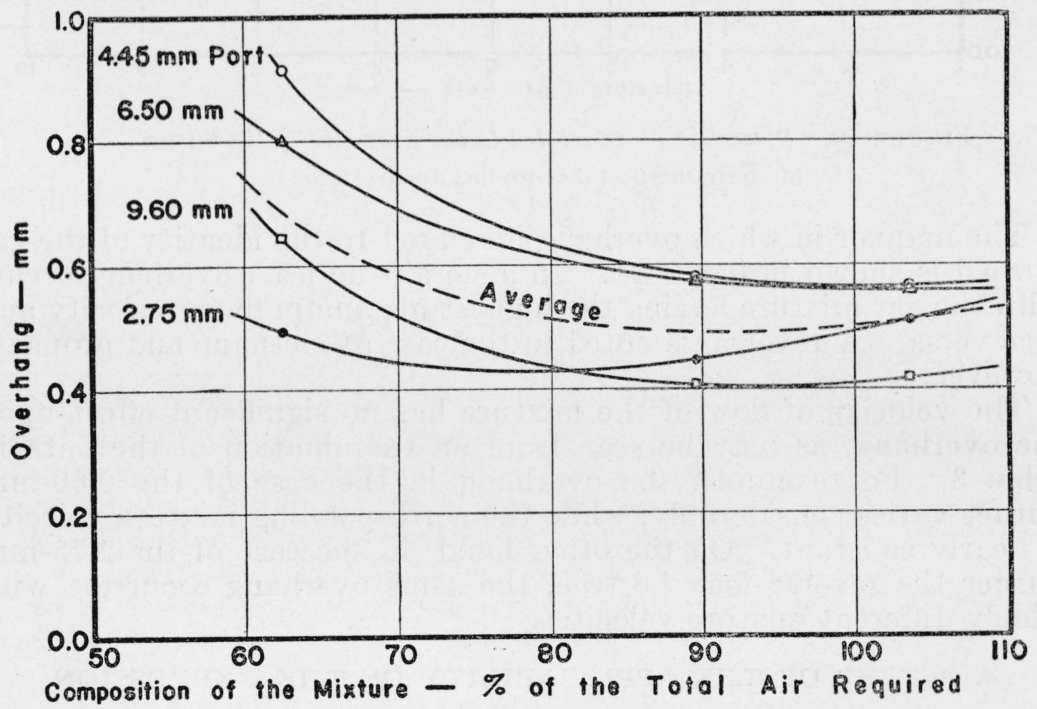

Figure 9.-The relation of "overhang" to the composition of the combustible mixture.

Measurements from the flames and ports of figure 7.

The average overhang on a given port has been plotted as ordinate and the composition of the mixture as abscissa in figure 9. These 
curves, with additional data in figure 11 show that the overhang is large in mixtures containing little primary air, decreases as the proportion of air is increased, and passes through a minimum in mixtures containing somewhat more air than the theoretical proportion. Although the data at hand do not all show it, the overhang again becomes larger with mixtures containing a large excess of air.

The average overhang for a given mixture has been plotted as ordinate and the size of the port as abscissa in figure 10, which shows the overhang to be slightly greater on the 4.45 and $6.50-\mathrm{mm}$ burners than on the 9.60 - or the 2.75 -mm burners. The difference between the largest and smallest overhang shown by the average curve is about $0.2 \mathrm{~mm}$ on ports which vary from 2.75 to $9.60 \mathrm{~mm}$, which is surprisingly small. In terms of the percentage of port radius, therefore, the overhang is much larger in the case of the smaller ports, as is shown in the right hand column of table 4 .

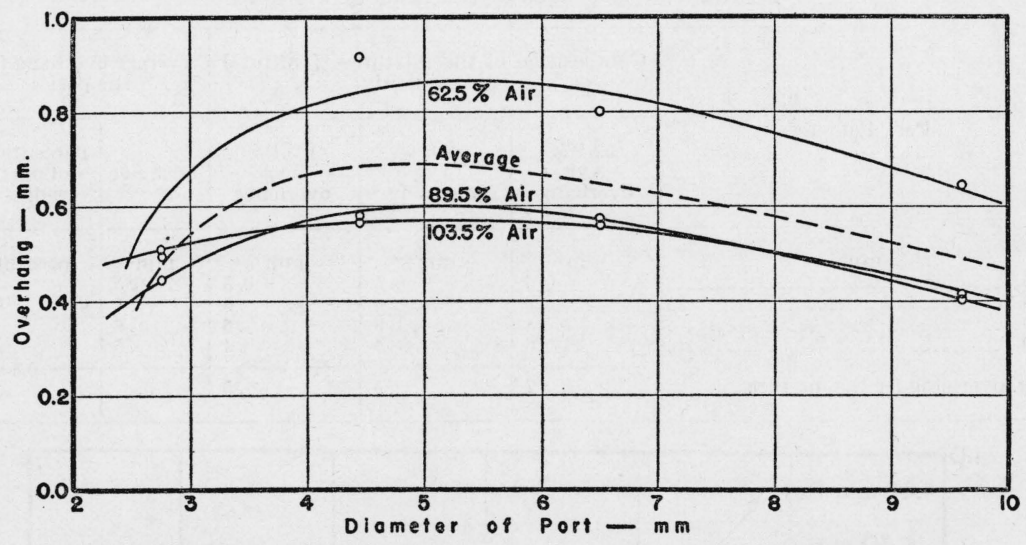

Figdre 10.- "Overhang" as related to the diameter of the burner port. Measurements from the ports and flames of figure 7.

The manner in which overhang is related to the identity of the gas burned is shown in figure 11. In general, the least overhang occurs with the gas mixture having the highest maximum flame velocity and vice versa. A reversal is noted in the case of methane and propane, however.

The velocity of flow of the mixture has no significant effect upon the overhang, as may be seen from an examination of the data in table 3. For example, the overhang in the case of the $9.60-\mathrm{mm}$ burner varies considerably, while the corresponding mixture velocity is nearly constant. On the other hand, in the case of the $2.75-\mathrm{mm}$ burner the reverse may be true, the same overhang occurring with widely different mixture velocities.

\section{A TEST OF THE APPLICABILITY OF THE EXPRESSION

$$
D_{\bar{v}}=0.707 D
$$

It is obvious that the correctness of the foregoing numerical results for the velocity of flame relative to the combustible mixture, and many of the conclusions based upon them, must rest upon the applicability 
of the assumption that $D_{\bar{V}}=0.707 D$, since this factor was used in all the computations of flame velocity based on measurements of the angle $\alpha$ which have been presented in this paper.

The theoretical derivation of this factor has been given on page 12 . Experimental data have been collected by workers in hydraulics who used much larger pipes. These data, while not conclusive, tend to indicate that the above factor is probably as close or closer to the truth than measurements of velocities by present means are capable of giving experimentally, so long as the flow remains laminar.

The relatively large departures from the shape of a geometrical cone exhibited by the flames of the $2.75-\mathrm{mm}$ burner (shown in fig. 7 ) and by those of set $\mathrm{A}$ with low primary air, and the fact that different numerical values for the flame velocity were obtained from measurements of these flames, suggested the possibility that some factor other than 0.707 might lead to more concordant results for the entire

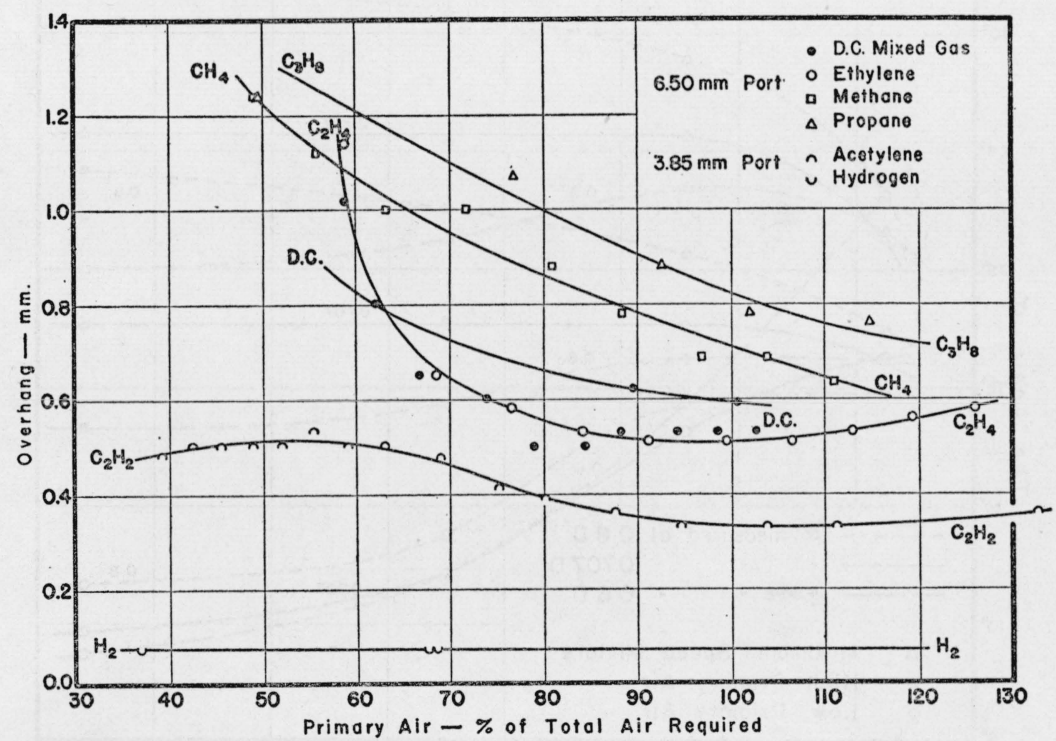

Figure 11.- "Overhang" as relaied to the identity of the combustible gas.

group. Accordingly, the angle $\alpha$ was remeasured for all the flames shown in figure 7, at the diameters $0.6 \mathrm{D}$ and $0.8 \mathrm{D}$ and the results were plotted in figure 12 with those obtained at $0.707 \mathrm{D}$.

It is seen that for both the mixture containing a high proportion of primary air and the maximum speed mixture the angle $\alpha$ is the same for the three larger burners and is somewhat smaller for the 2.75 -mm burner when $\alpha$ was measured at $0.707 D$. $\alpha$ increases with increasing $D$ when measured at $0.8 D$, and decreases with increasing $D$ when measured at $0.6 D$. For the rich mixtures $\alpha$ tends to decrease with increasing $D$ whether measured at $0.6 D, 0.707 D$, or $0.8 \mathrm{D}$.

The constancy of the value of $\alpha$ when measured at $0.707 D$ (in the cases of the lean and maximum speed mixtures when using the three larger burners) and its variation in opposite directions when $\alpha$ was 
measured at $0.6 \mathrm{D}$ and $0.8 \mathrm{D}$, indicates that the range of variation of this factor within which the value of $\alpha$ is independent of the size of the burner port is very limited; and also that the factor which yields a constant value of $\alpha$ lies much closer to 0.7 than to 0.6 or 0.8 .

The above findings point to the conclusion that within a limited range of port sizes and a limited range of composition of the combustible mixture, there is a very limited portion of the flame surface the slope of which has not been affected by the distortion at the base or at the tip.

This conclusion is partially corroborative of the conclusion of Ubbelohde [4] mentioned on page 11 that the rounded tip and curved base represented deviations from the normal, but indicates that the

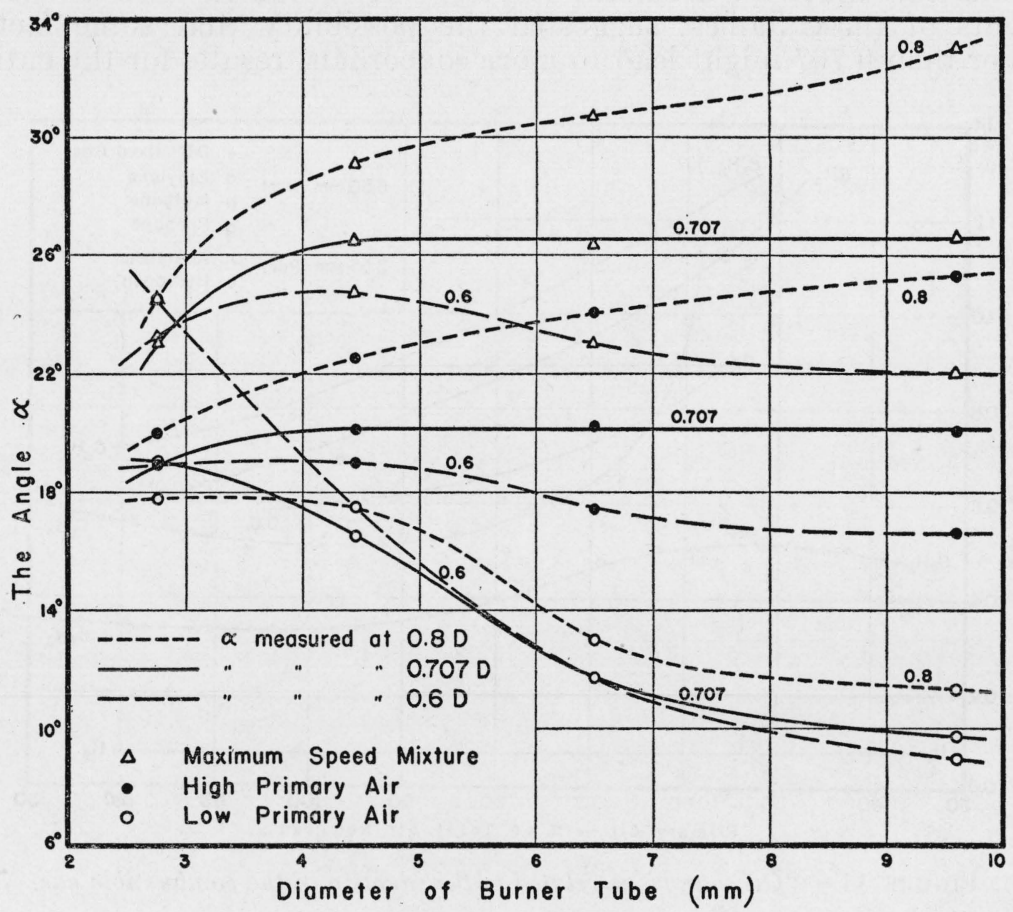

FIGURE 12.-Location of the part of the flame surface at which a is independent of the diameter of the burner tube.

Measurements from the flames of figure 7.

deviations extend much further from tip and base than he supposed. Ubbelohde considered that the straight portion of the flame surface was unaffected by these disturbing influences and measured the angle between this and the axis. As will be seen from the discussion of figure 13 (III), the entire flame surface, unaffected by secondary influences, should be concave upward rather than straight. In this connection it is significant that when $\alpha$ was measured at $0.707 D$, on flames with which the angle was found to be independent of the diameter of the port, the points marked on the images all fell on concave portions of the flame surfaces. 
The part of the flame surface involved when $\alpha$ is measured at $0.707 D$, using suitable burners and mixtures, is probably affected little or not at all by those things which affect the tip and base, and which may even overlap in such cases as those of the rich mixture on the 2.75 -mm burner.

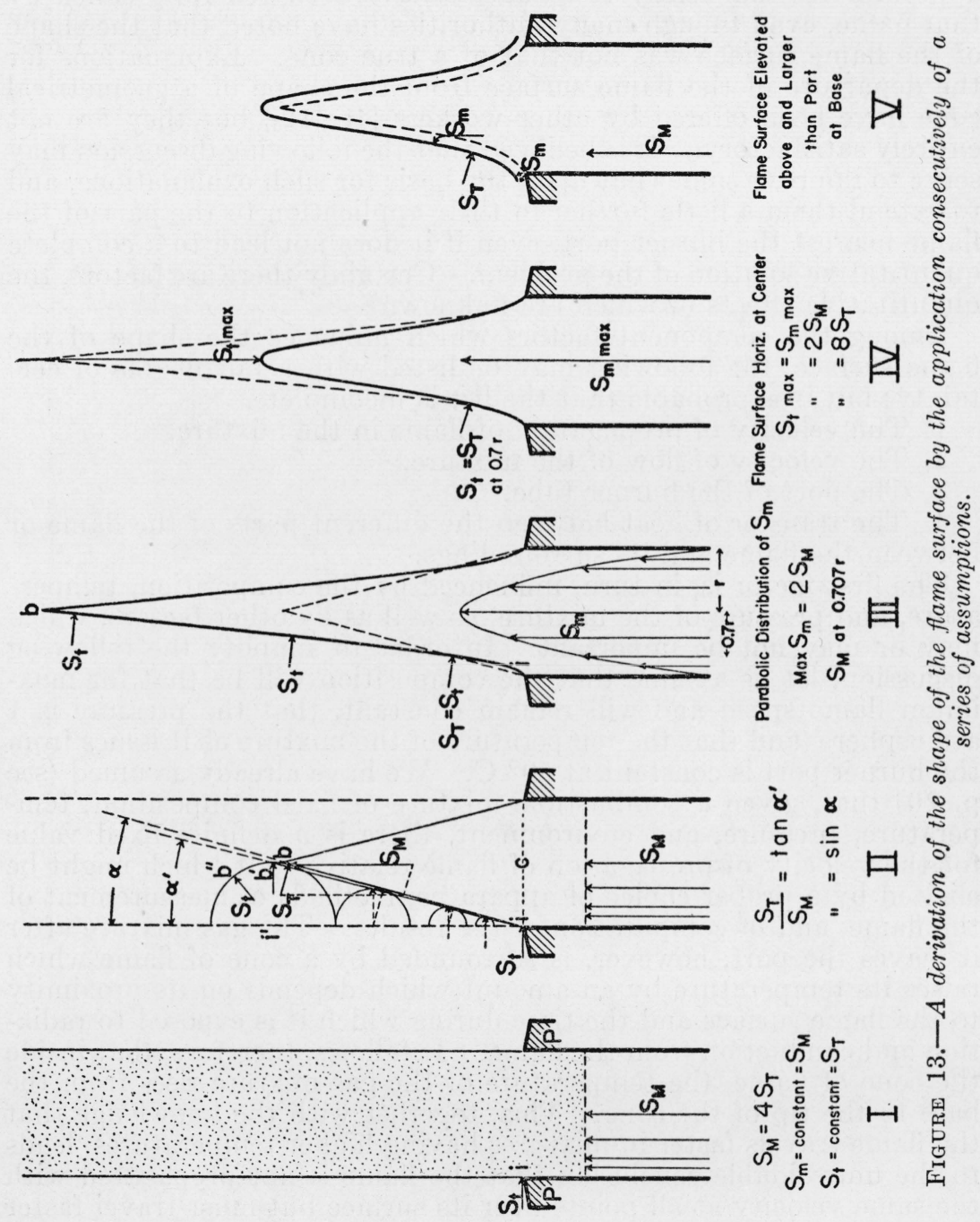

In view of the above, it seems probable that the expression $S_{\mathrm{T}}=S_{\mathrm{M}}$ $\sin \alpha$ is capable of yielding numerical results which are independent of the diameter of the port. But it is also probable that this is true only in case the composition of the mixture is near the theoretical and the burner port is over $4 \mathrm{~mm}$ in diameter. 


\section{SHAPE OF THE FLAME SURFACE AS A RESULTANT OF SEVERAL VARIABLE COMPONENTS}

The shape of the figure assumed by the flame front resulting when a burning stream of combustible mixture issues from a burner tube approximates sufficiently to a cone to have been generally called by that name, even though many authorities have noted that the shape of the flame surface was not that of a true cone. Explanations for the departure of the flame surface from the shape of a geometrical cone have been offered by other workers [4], [12], but they are not entirely satisfactory. It is believed that the following discussion may serve to improve somewhat upon the basis for such explanations, and to extend them a little further in their application to the part of the flame nearest the burner port, even if it does not lead to a complete quantitative solution of the problem. Certainly there are factors, the quantitative effects of which are unknown.

Among the component factors which influence the shape of the flame surface, the following may be listed with a fair degree of certainty; but it is probable that the list is incomplete.

1. The velocity of propagation of flame in the mixture.

2. The velocity of flow of the mixture.

3 . The port of the burner tube.

4. The transfer of heat between the different parts of the flame or between the flame and its surroundings.

The first factor is, in turn, influenced by the composition, temperature, and pressure of the mixture, as well as by other factors, which may or may not be important. In order to simplify the following discussion, let us assume that the composition will be that for maximum flame speed and will remain constant, that the pressure is 1 atmosphere, and that the temperature of the mixture as it issues from the burner port is constant at $50^{\circ} \mathrm{C}$. We have already assumed (see p. 20) that, given a combustible mixture of fixed composition, temperature, pressure, and environment, there is a definite fixed value for the velocity of propagation of flame relative to it which might be elicited by a proper choice of apparatus, methods of measurement of the flame, and of computation of the results. The gas mixture after it leaves the port, however, is surrounded by a cone of flame which raises its temperature by an amount which depends on its proximity to the flame surface and the time during which it is exposed to radiation and conduction from the flame. It follows, therefore, that inside the cone of flame, the temperature of the gas mixture rises from the base to the tip of the cone. This, together with the knowledge that the flame travels faster in mixtures having higher temperatures, leads to the unavoidable conclusion that the flame is not propagated with the same velocity at all points over its surface but must travel faster at some points than at others.

The second factor is determined only indirectly in the present study. The volume of gas passing per unit of time is divided by the area of the burner port, which yields the average or mean velocity of flow of the gas mixture through the port. Assuming laminar flow, 
which has already been justified,,$^{12}$ there are several facts to be noted. On both theoretical and experimental grounds it can be stated: (1) that the distribution of velocities will be parabolic; (2) that the gas mixture will flow with its average velocity at a distance from its axis of 0.7 the radius of the circular port; and (3) that the maximum velocity at the axis will be twice the average velocity. In addition, it has been found that the diameter of a stream of unburned gas issuing from the port remains substantially equal to the diameter of the port for some 10 to 15 diameters - until the sharp boundary is broken up by turbulence. This indicates that there is no significant expansion of the stream to be expected as a result of any pressure change on leaving the port. There is, however, reason to expect that the stream of mixture surrounded by a cone of flame will rise in temperature after it leaves the port. This increase of temperature may be expected to cause a corresponding expansion equal in all directions relative to the moving stream, and consequently to deflect it outward from the axis by an amount which is proportional to the increase in the absolute temperature and which also increases as the distance from the axis increases.

The third factor, the port, exerts its influence upon the shape of the flame surface in at least two ways, one of which has been treated above and illustrated in figure 7. Restricting discussion to circular ports, the diameter affects the shape less than it does the size of the flame surface (other factors remaining constant). The effect illustrated may be accounted for if the dimensions of the temperaturegradient zones ${ }^{13}$ remain about the same, regardless of the size of the port. Thus the same dimension becomes larger relative to a small port than to a large one and the effeet is to broaden the flame surface relative to the port. Secondly, the material of which the port is made might be expected to influence the shape of the flare at the base of the flame surface. A material of low thermal conductivity would, by becoming hotter itself, allow the flame to approach nearer the rim of the port than would be the case where a material of high conductivity forces the temperature drop from flame to the initial temperature to take place almost entirely within the gas mixture alone. In the case at hand, where the port is made of material of high heat conductivity and maintained at the same temperature as the combustible mixture emerging from it, it is not clear how the port can exert any cooling effect upon the flame surface that would not also be exerted by the mixture itself at some distance above the port rim. Consequently, it is doubtful if the cooling effect of the port can play as important a part in the distortion of the flame surface at the base as has so often been attributed to it.

Other sources of heat, such as the secondary combustion which usually surrounds the primary cone of a flame, influence the shape of the primary flame surface. First, the flare at the base of the cone is slightly decreased and, in effect, drawn closer to the rim of the port; and, secondly, the heat transmitted to the unburned mixture is in-

12 With the assumption of laminar flow, which has been justified, there has also been made a second assumption which has not been justified; i. e., that the parabolic distribution of velocity which exists within the tube persists during and after emergence from the port, at least until the tip of the cone is reached. Direct experimental evidence on this point is lacking. From purely theoretical considerations one must conclude that some modification will occur which would take the form of a decrease in the velocity of flew at the center of the stream and in an increase at the surface. Whether the change is great enough to be significant in the short space involved is not known.

13 See discussion of gradient layer on p. 38 . 
creased, causing an increase in the flame velocity, which, in turn, results in a decrease in the size of this cone of mixture. The effect depends, of course, upon the composition of the primary mixture, being large when the proportion of primary air is low, and negligibly small when the proportion of air approaches or exceeds the theoretical ratio.

An attempt has been made in figure 13 to illustrate some of the possible effects of several factors considered separately on the ultimate shape of the surface of a flame. I represents a port $\mathrm{P}$, through which a combustible mixture is flowing vertically upward.

Let $S_{\mathrm{t}}$ be the velocity of propagation of the flame surface relative to the mixture, or its speed of transformation by the flame, at any point. Let $S_{\mathrm{m}}$ be the velocity of the combustible mixture at any point. Let $S_{\mathrm{M}}$ be the mean velocity of the combustible mixture, and $\alpha$ the angle between flame surface and axis. It will be shown shortly that $S_{\mathrm{T}}$ may now be defined by the equation $S_{\mathrm{T}}=S_{\mathrm{M}} \sin \alpha$ (when $\alpha$ is measured at the point on the radius where $S_{\mathrm{M}}$ is found, namely, 0.7 the distance from center to rim of the port). The velocity of flow, $S_{\mathrm{m}}$, is for the moment considered to be uniform across the section of the port and equally numerically to the mean velocity of flow in a tube passing gas at the same rate. This is represented symbolically by $S_{\mathrm{M}}$. The composition and mean velocity of the mixture are so chosen that $S_{\mathrm{M}}=4 S_{\mathrm{T}}$, where $S_{\mathrm{T}}$ is the rate at which flame is propagated relative to the mixture.

If the combustible mixture be ignited at any point, $i$, the flame will travel with equal velocity in all directions in the mixture, its surface, therefore, being spherical.

In II, the direction of travel of the flame is indicated as radial by the vectors $S_{\mathrm{t}}$ and $S_{\mathrm{r}}$, which are equal, and whose length indicates the velocity of travel of the flame. During the time required for the flame to travel from $i$ to the center of the stream, the mixture has moved upward from $i$ to $i^{\prime}$, so that the flame front arrives at $b^{\prime}$ just as if it had started from $\mathrm{i}^{\prime}$ in a stationary mixture. However, in traveling, the spherical flame front, simultaneously rising vertically and expanding radially, describes the bounding line ib. The direction of advance of the elements of flame front which together consticute the line ib is, of course, radial in any sphere. The radius of a circle which passes through the point at which a line is tangent to the circle must be perpendicular to the tangent line. Therefore, the flame front must advance in a direction normal to itself. (See Huyghens' principle of the propagation of light). With the flame advancing in a direction normal to itself, it is now evident that $S_{\mathrm{T}}$, the vector forming a part of the radius $i^{\prime} b$, divided by the vector $S_{M}$ is equal to $\sin \alpha$, the angle between surface and axis of the conical flame front. The relationship $S_{\mathrm{T}}=S_{\mathrm{M}} \sin \alpha$ is thus derived directly from the direction of propagation of the flame front, and serves to define $S_{\mathrm{T}}$ in terms of $S_{\mathrm{M}}$ and $\alpha$, which have been defined above.

Thus far, we have made three arbitrary assumptions, i. e., $S_{\mathrm{M}}=4 S_{\mathrm{T}}$, $S_{\mathrm{m}}$ is constant and equal to $S_{\mathrm{M}}$, and $S_{\mathrm{t}}$ is constant and equal to $S_{\mathrm{T}}$. The second of these, if true, would greatly simplify the determination of flame velocity since one need only adjust $S_{\mathrm{M}}$ to make $\sin \alpha$ equal 1 , in which case the advancing spherical element would describe the bounding line ic, forming a plane surface at the mouth of the port; $\alpha=90^{\circ}$, and $S_{\mathrm{T}}=S_{\mathrm{M}}$. 
Actually, within the burner tube, $S_{\mathrm{m}}$ is distributed parabolically over the section of the port as indicated in III. This having been determined by experiment, the following facts may be derived theoretically as well as experimentally. (1) $S_{\mathrm{m}} \max =2 S_{\mathrm{M}}$; and (2) $S_{\mathrm{M}}$ occurs at $0.7 r$ from the axis. Assuming that the parabolic distribution of velocity remains unchanged for at least 4 diameters beyond the port, III has been constructed to conform to these conditions; and the conical surface derived in II, and shown dotted in III, has been modified accordingly. In moving from the port rim to the axis, the flame simultaneously rises less near the rim, the same distance as before at $0.7 r$, and twice as far at the center. The resulting flame surface is indicated by the solid line, ib, $S_{\mathrm{t}}$ still being assumed constant and equal to $S_{\mathrm{T}}$.

Obviously the shape delineated in III does not correspond to that of an actual flame. For one thing, no flame has a perfectly sharp point, but is rounded off somewhat as indicated by the solid line in IV. Regardless of the factors which may be operating to produce the effect, it is apparent that at the center the surface must be horizontal. Here $\alpha$ equals $90^{\circ}$ and consequently $S_{\mathrm{t}}=S_{\mathrm{m}}$; or, the direction of advance of the flame front being normal to its surface must be vertically downward in the same line as the velocity of the mixture, and, since the surface moves neither upward nor downward, $S_{\mathrm{t}}$ must equal $S_{\mathrm{m}}$. In either case one arrives at the same result. $S_{\mathrm{t}}$ at the center must equal $S_{\mathrm{m}} \max$, which is equal to $2 S_{\mathrm{M}}$. But $S_{\mathrm{M}}$, in turn, has been assumed from the beginning to equal $4 S_{\mathrm{T}}$. Therefore, $S_{\mathrm{t}}$ at the tip is 8 times $S_{\mathrm{T}}$; and the third of our original arbitary assumptions (that $S_{\mathrm{t}}$ is constant and equal to $S_{\mathrm{T}}$ ) has been shown to be invalid as far as the tip of the flame is concerned. The first still holds, for IV was so drawn that the direction of advance of $S_{\mathrm{T}}$ in IV is the same as that in II. Therefore, $S_{\mathrm{M}}$ still equals $4 S_{\mathrm{T}}$.

While the solid line delineating the flame surface in IV corresponds approximately to the outline of an actual flame over most of its length, it fails to do so at the base where the flame approaches nearest the rim of the port. The base of an actual flame has a larger diameter than the port and locates itself at a measurable distance above it, as is indicated in a somewhat exaggerated manner in V. For purposes of discussion we may assume that in the exceedingly thin flame front there is some definite temperature which is the same over the entire surface of the flame. The port is maintained at a temperature of $50^{\circ} \mathrm{C}$ by continuously replacing the water in the jacket surrounding the burner by fresh water at $50^{\circ}$. It seems reasonable to suppose that the flame would actually touch the port if the port were at the flame temperature, and conversely, that the flame does not approach nearer the port than it does because the distance separating them is required in which to raise the gas mixture from the temperature of the port to the temperature of the flame front.

That portion of the combustible mixture in contact with the rim of the port has an upward velocity which is substantially zero. That near the wall has only a slightly greater velocity. When this mixture rises above the level of the port rim into the vicinity of the flame front it receives heat by conduction and radiation as does the port. It expands by an amount corresponding to its rise in temperature, and having only a slight vertical motion its expansion may be so great in comparison that the resulting direction of its motion may be as much 
outward as upward, as indicated by the small arrows at the left rim in V. In addition to this lateral expansion, it has been supposed that by the time the primary mixture at the rim of the port has reached the short distance from the rim at which the flame can persist, some interdiffusion of the primary mixture with the outside air will have taken place. ${ }^{14}$

Since the shape of the flame surface is a resultant of the velocity and direction of the mixture and the flame propagation, among other factors, this view of the situation at the port rim can readily account for the outward flare of the flame surface at this point, and consequently for the overhang of the flame relative to the port.

The magnitude of $S_{\mathrm{m}}$ is here largely determined by thermal expansion, and the space between flame and port rnay be considered to represent the distance ahead of the flame surface at which the source of heat at the temperature of the flame is able to maintain a temperature of $50^{\circ} \mathrm{C}$ by whatever means against the motion of the oncoming mixture. The flame does not dip down inside the rim of the port. The velocity of the mixture becomes greater as the center is approached. The temperature of the mixture is maintained at $50^{\circ}$ $\mathrm{C}$ by being continuously replaced by fresh mixture at $50^{\circ} \mathrm{C}$ at a rate which is greater than that at which the flame is able to advance, even near the rim of the port, and at a still faster rate as the center is approached. For these reasons, regardless of which mechanism of propagation may be assumed to operate, it seems probable that there may be a thin gradient layer, less than $1 \mathrm{~mm}$ thick, underlying the entire flame surface, in which the temperature rises rapidly from that of the mixture near the center to that of the flame front, and the thickness of which may be inferred from the distance of approach of the flame to the port.

This conclusion is supported by such evidence as the sharpness of the outline of the surface of an advancing spherical flame front of $\mathrm{CO}-\mathrm{O}_{2}$ exploding in a bubble photographed by transmitted light [13]. Both the bubble and the flame are evidenced by the change in the optical properties of the material through which the light passes. In the case of the flame, this is caused by the difference between the temperature of the unburned gases ahead of the reaction zone and the much higher temperature of the gases constituting the reaction zone.

If this change had been gradual, a proportionately slow change in the optical properties and a correspondingly diffuse image would have resulted. Actually, the image of the flame front is surprisingly sharp, which indicated a correspondingly steep temperature gradient. Furthermore a thermocouple, introduced from below into the center of the volume outlined by the mixture, and moved laterally toward the flame surface, shows only a gradual rise in temperature until it is practically in contact with the flame, when it rises very rapidly.

\footnotetext{
14 Ubbelohde and Koelliker [4], in explaining why the flame lifts off the port under certain conditions, assume that outside or secondary air diffuses or flows inward under the lower rim of the flame and by increasing the proportion of air in the combustible mixture at this point may, in lean mixtures, cause the flame veløcity to be lowered even to zero, thus allowing the flame to leave the port.

Some experiments in which fine carbon particles (soot) were introduced into the air around the burner throw light on the validity of this explanation. When the particles of soot entered the primary air openings of an ordinary bunsen burner they became incandescent on passing through the inner cone of the flame and indicated clearly the direction of flow of the gases in which they were suspended. When the jacketed burner shown in figure 2 was supplied with primary air from the laboratory air line no incandescent particles were observed, showing that air surrounding the burner does not flow in under the base of the flame at the port. Any explanation of phenomena associated with the base of the fiame must, therefore, be explained on some basis other than by the accession of secondary air into the combustible mixture by any process other than diffusion.
} 
Such a gradient layer, greatly exaggerated in thickness, is indicated in $\mathrm{V}$ by the dotted line underlying the flame surface. There is at hand insufficient evidence to decide whether or not the gradient layer changes in thickness toward the tip, but it is evident that when the opposite sides of its inner surface come together, so that the two layers mutually affect each other, the rapid acceleration of the flame movement and the rounding off of the tip of the flame surface are inevitable.

As has been mentioned above on page 35 , a rise in temperature may be expected to result in a corresponding expansion of the unburned mixture. It follows from what has just passed that most of the lateral motion imparted to the mixture will be imposed in this thin gradient layer, and consequently will affect the position of the mean velocity diameter only slightly, even though the mixture may be traveling in a direction normal to the flame surface as it passes through it. That the mixture probably does pass through the flame in approximately this direction is indicated by the direction of the emergence of fine carbon particles introduced as soot into the air around a bunsen burner. The arrow marked $\mathrm{S}_{\mathrm{n}}$, passing through the gradient layer in $\mathrm{V}$, indicates the probable direction of flow of the mixture as it approaches the flame surface.

On account of the sharp changes in the optical properties of the gases, as shown by spark photographs of flame fronts, as well as the other evidence for the presence of a thin gradient layer, it does not seem possible, on the basis of an increase in the temperature of the combustible mixture, to account for as great an increase in the flame velocity at the tip of the flame as the derivation given in figure 13 indicates. Neither does it seem possible on this basis to account for appreciable increases in the flame velocity extending downward much below the tip of the flame.

The unreasonably large increase in flame velocity at the tip and the relatively large disparity in shape between the solid and dotted outlines of the flame surface in IV of figure 13 may be accounted for if the parabolic distribution of velocity does not persist unchanged beyond the port, as was assumed.

It is certainly true that after emerging from the port the moving stream is surrounded by a stationary mass of air which exerts a frictional retarding effect just as the metal walls of the tube do. The surrounding air, however, is not rigid and cannot maintain itself stationary against the tendency of the moving stream to set it in motion. Laminas of surrounding air can only be set in motion by the forward drag of laminas of the moving gas stream next inside them. These laminas, in turn, have a higher velocity than they had when in contact with the rigid walls of the burner tube.

The energy required to set in motion laminas of surrounding air must come from the kinetic energy of the moving stream, with a consequent decrease in its velocity as a whole, since no further pressure gradient exists after the stream emerges from the port. Superposed upon this effect, the laminas near the center of the moving stream have their velocities reduced to correspond to the increased velocity of those at the surface, as a result of the lack of a rigid stationary retarding effect. This redistribution of velocities is such as to maintain the momentum of the stream as a whole at the rate of decrease occasioned by the loss of energy just mentioned.

The magnitude of these combined effects may be expected to vary with different gases. The solid outline in IV of figure 13 would result 
if $S_{\mathrm{m}} \max$ had a value more nearly $1.1 S_{\mathrm{M}}$ than $2.0 S_{\mathrm{M}}$. This would lead to a value of $S_{\mathrm{t}}$ at the tip of $4.5 S_{\mathrm{T}}$ instead of $8 S_{\mathrm{T}}$. It would also permit the supposition that $S_{t}$ remained substantially equal to $S_{\mathrm{T}}$ until the overlapping of the gradient zones at the tip occurred. A fourfold increase at this point still seems high but not entirely unreasonable.

Some experimental work has been done by various people and several postulates have been offered concerning mechanisms of propagation of flame and the transfer of energy by radiation, by activated particles, etc. [14], which have a bearing for the most part on the character of the flame front and gradient layer, but which would affect in no significant way the derivation of the shape of the flame surface just presented. Their discussion is beyond the scope of this paper.

A local value of $S_{\mathrm{t}}$ at the tip, which is actually several times as great as $S_{\mathrm{T}}$, must be the result of changes in the physical or chemical condition of the gas mixture. Without attempting in this paper to estimate the relative importance of such real or imaginary effects as those mentioned above, it is certain that if they occur at all their effects must be more pronounced near the tip and result in an inward bending of the flame surface.

The experimental fact that the shape of one part of the flame surface is modified by proximity to the burner, and that of another part by proximity to other parts of the flame, would lead us to expect what we find-that the most consistent results for flame velocity should be obtainable when using large burners rather than small ones, and when measurements are made on the flame surface at some distance from either base or tip rather than when the entire surface is used.

\section{SUMMARY AND CONCLUSIONS}

A description has been given of the equipment and procedure used by the authors to determine the velocity of propagation of flame in mixtures with air of carbon monoxide, hydrogen, acetylene, methane, ethylene, and propane. A modification of the general "burner method" was chosen after a review of the methods employed by other workers, and because the results obtained were to be applied to the study of burners. The angle $\alpha$ between the axis and the tangent to the flame surface was measured at a point $0.7 r$ from the axis, where the actual velocity of the stream of gas equals the mean velocity. The mean velocity of the mixture, $S_{\mathrm{M}}$, was determined by dividing the measured volume rate of flow of the mixture by the area of the burner port. The flame velocity $S_{\mathrm{T}}$ was then computed from the relationship $S_{\mathrm{T}}=S_{\mathrm{M}} \sin \alpha$.

Attention is called to the fact that "flame velocity" like "flame temperature", etc., is not a characteristic of a gas itself, but a property of the system as a whole, including the apparatus; and the identity of the gas can be considered as only one of several factors which, taken together, determine the numerical values in a given case. Also, such data must be used with the knowledge that the numerical values may or may not be applicable to any particular case in question.

Data are presented in the form of curves, with the compositions of the mixtures plotted in terms of the air required to combine with the gas, to place the different fuels on as nearly the same basis as possible for comparison. It is concluded, however, that the only points on 
the curves of two or more fuel gases which even approach suitability for a direct comparison are the maxima.

An attempt has been made to isolate and determine the effect, on the numerical result, of the velocity of flow of the combustible mixture, the diameter of the burner port, the method of measuring the photographs (angle between surface and axis, versus total area of flame surface), the overhanging base of the flame, and the assumed location of the mean velocity in the stream of combustible gas mixture. The assumption has been made that in any combustible mixture of gases of given composition, temperature, pressure, and environment, there is a definite fixed value for the velocity of propagation of flame relative to the mixture, which may be elicited by a proper choice of apparatus, methods of measurement and of computation; and that different values are obtained by different means because of effects imposed upon the numerical result by the methods of measurement and computation, or by the apparatus; and not because of differences in the flame velocity itself.

It was determined that the numerical result obtained by the method described was independent of the velocity of flow of the gas mixture within the precision of the measurements, the average deviation of the individual determinations from the mean being about 2 percent.

The base of the flame surface was found to be somewhat larger in diameter than the port and suspended a short distance above it. This "overhang" was found to be nearly the same for large as for small ports, and consequently was a larger fraction of the radius of the latter, amounting to more than 30 percent of the port radius in the case of the two smaller burners. This was sufficient to lower the numerical results considerably as compared with those obtained with larger burners, when the results were computed from measurements of the surface area of the flames. The larger ports produce flame surfaces with relatively sharp tips and sides which are concave outward near the base. With smaller ports the flame tends to become thimble-shaped, with the tip broadened into a dome. Similar changes in the shape of the flame surface occur with the same port as the proportion of air in the mixture is reduced. The relationship of overhang to the proportion of air in the gas mixture and to the identity of the combustible gas is also shown.

It is concluded that when the burner method is used, the shape of the flame surface must not depart markedly from that of a geometrical cone, if computations based on the actual area of the flame surface are expected to yield substantially the same results as those based on measurements of the angle between the flame surface and its axis, and only then can either result be considered to be approximately correct. To approximate sufficiently to a geometrical cone the flame must result from a mixture in laminar flow, in which the flame velocity is near its maximum, and when the burner ports are not much smaller than $4 \mathrm{~mm}$ in diameter. Under other conditions both methods of measurement yield results which depend on the size of the burner, especially when using mixtures contaning much less than the theoretical proportion of air or burners smaller than $4 \mathrm{~mm}$ in diameter. However, the angle is affected much less than the area by the relative changes in overhang and shape of the flame which accompany changes in the size of the port. 
The fact that the angle between the surface and axis of the flame is independent of the diameter of the burner tube when the angle is measured at a point $0.707 r$ from the axis, and varies in opposite directions when measured at $0.6 r$ and $0.8 r$, (in the cases of the lean and maximum-speed mixtures when using the three larger burners) indicates that the angle is independent of the size of the burner only within a limited range of variation of this factor, and that the value of the factor which yields a constant value of the angle lies much closer to 0.7 than to either 0.6 or 0.8 .

These and other facts lead to the conclusion that, even with ports larger than $4 \mathrm{~mm}$ and with mixtures in nearly theoretical proportions, there is a very limited portion of the flame surface which has been affected little or not at all (in slope) by the factors which cause the distortion at the base and at the tip.

Within these limitations it seems probable that the expression $\mathrm{S}_{\mathrm{T}}=S_{\mathrm{M}} \sin \alpha$ is capable of yielding numerical results which are independent of the diameter of the port.

An attempt has been made to derive the shape of the flame surface by the application consecutively of a series of facts and of assumptions based on facts. The derivation leads to the conclusion that a local value of the flame velocity at the tip, which is several times the average as determined, may exist as the result of changes in the physical or chemical condition of the mixture. Hence, the tip of the cone is rounded off. It is demonstrated, by an application of Huyghens' principle, that the flame front advances in a direction normal to its surface.

Since the temperature of the mixture is maintained inside the cone of flame by the mixture being continuously replaced at a rate greater than that at which the flame can advance, it seems probable that most of the temperature rise and most of the lateral motion produced by expansion may take place within a thin gradient layer underlying the entire flame surface, and that the thickness of the layer may be inferred from the distance of approach of the flame to the port. It is not clear how the port can exert any cooling effect upon the flame surface that would not also be exerted by the mixture itself at some distance above the port rim. Consequently, it is doubtful if the cooling effect of the port can play as important a part in the distortion of the flame surface at the base as has been attributed to it. This distortion may be more reasonably accounted for by the effect of heat from the flame upon the direction and magnitude of the motion of the gas mixture at the rim of the port.

The rounding off of the flame surface well below the tip is probably not the result of a progressive increase in flame velocity caused by an increase in the temperature of the mixture, but is more likely caused by a redistribution of velocities in the stream of mixture after leaving the burner tube.

Finally, it is concluded that while the range of operations within which the burner method is capable of giving reliable results is restricted considerably by the effect of several experimental variables on the shape of the flame surface, yet it appears to be as simple and useful as any of the methods available at present. However, a knowledge of its limitations is essential if erroneous conclusions from results obtained with it are to be avoided. 
The authors desire to make acknowledgment to Messrs. John H. Eiseman, Nelson L. Miller, and Cecil J. Merritt for able assistance in conducting the experimental work involved in collecting the data presented in this paper.

\section{REFERENCES}

[1] R. Bunsen, Pogg. Ann. 131, 161 (1866).

[2] M. Gouy, Ann. chim. Phys. [5] 18, 27 (1879)

[3] W. Michelson, Flame velocity of gas mixtures. Ann. Physik [3] 37, 1-24 (1889).

[4] L. Ubbelohde and E. Koelliker, Information about the inner cone of the bunsen flame. J. Gasbeleucht. 59, 49-57 (1916).

[5] F. W. Stevens, Nat. Advisory Comm. Aeronaut. Rep. 305, (1929).

[6] F. W. Stevens, A Constant Pressure Bomb. Nat. Advisory Comm. Aeronaut. Rep. 186 ,(1923); J. Am. Chem. Soc. 48, 1896 (1926).

[7] L. Ubbelohde and M. Hofsäss, The flame velocity in the inner cone of the bunsen flame. J. Gasbeleucht. 56, 1253-62 (1913).

[8] H. Mache, Die Physik der Verbrennungserscheinungen (Leipzig, 1918).

[9] W. R. Chapman and R. V. Wheeler, The Movement of the medium in which the flame travels. J. Chem. Soc. 38-46 (1927).

[10] J. Corsiglia, New method for determining ignition velocity of air and gas mixtures. Am. Gas Assn. Mo. 13, 437-42 (1931).

[11] L. Ubbelohde and M. Hofsäss, The flame velocity in the inner cone of the bunsen flame. J. Gasbeleucht, 56, 1225-32 (1913).

[12] K. Bunte and W. Litterscheidt, Ignition velocity of gas mixtures. Gas. u. Wasserfach $\mathbf{7 3}, 837-42$ (1930).

[13] E. F. Fiock and C. H. Roeder, Nat. Advisory Comm. Aeronaut. Tech. Rep. 532, (1935).

[14] B. Lewis and G. von Elbe. On the theory of flame propagation. J. Chem. Phys. 2, 537-46 (1934).

Washington, April 21, 1936. 